\title{
Research Paper \\ The Effect of a Multidimensional Intervention Program (Sensory-Motor Integration Training for Child and Parent) on Reading Attitudes and Performance of Students with Dyslexia
}

\author{
Roghayeh Karimi Lichahi ${ }^{1}$, Bahman Akbari ${ }^{* 2}$, Abbas Ali Hoseinkhanzadeh ${ }^{3}$, Samereh Asadi Majreh ${ }^{4}$ \\ 1. Ph.D. Student of Psychology, Department of Psychology, Rasht Branch, Islamic Azad University, Rasht, Iran \\ 2. Professor, Department of Psychology, Rasht Branch, Islamic Azad University, Rasht, Iran \\ 3. Invited Professor, Department of Psychology, Rasht Branch, Islamic Azad University, Rasht, Iran \\ 3. Associate Professor, Department of Psychology, Faculty of Literature and Humanities, University of Guilan, Rasht, Iran \\ 4. Assistant Professor, Department of Psychology, Rasht Branch, Islamic Azad University, Rasht, Iran
}

Citation: Karimi Lichahi R, Akbari B, Hoseinkhanzadeh AA, Asadi Majreh S. The effect of a multidimensional intervention program (sensory-motor integration training for child and parent) on reading attitudes and performance of students with dyslexia. J Child Ment Health. 2021; 8 (2):1-16.

URL: http://childmentalhealth.ir/article-1-1127-en.html
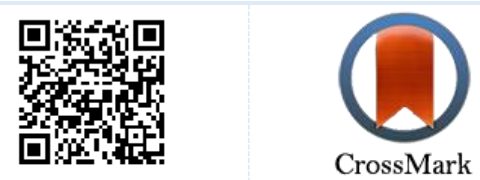

$10.52547 / \mathrm{jcmh} .8 .2 .1$

20.1001.1.24233552.1400.8.2.3.4
A R T I C L E I N F O

\section{Keywords:}

Multidimensional

intervention,

sensory-motor

integration,

child and parent,

reading attitudes and

performance,

students with dyslexia

Received: 13 Mar 2021

Accepted: 14 Jun 2021

Available: 11 Sep 2021

\section{A B S T R A C T}

Background and Purpose: Reading attitudes and performance of students with dyslexia can play a focal role in their success or failure in academic performance. Therefore, the present study was conducted to investigate the effect of a multidimensional intervention program (Sensory-Motor Integration Training for Child and Parent) on reading attitudes and performance of students with dyslexia.

Method: The study was designed as a quasi-experimental pre-test-post-test study with a control group. The population includes students with dyslexia referred to educational and rehabilitation centers of specific learning disabilities in Rasht city in the 2019-20 academic year. A sample of 40 participants was selected by the convenience sampling method. They were randomly assigned to the experimental and control groups. The instruments of the study included the $4^{\text {th }}$ edition of the Wechsler Children's Intelligence Scale (2003), the Reading Attitude Scale (Mckenna and Kear, 1990), and the Reading and Dyslexia Test (Kormi Nouri and Moradi, 2005). The multidimensional intervention program was performed in eight 60-minutes-sessions only for the experimental group, and the control group received only their routine training centers.

Results: The results of the analysis of covariance showed that the training program of sensory-motor integration for children and parents has a significant effect on the reading attitudes and performance of students with dyslexia $(\mathrm{P}<0 / 01)$.

Conclusions: According to the results of the present study on the effectiveness of the sensory-motor integration program with mother-child interaction ' the mother-child interactive test based on this method can be used as a suitable option in designing psychological and educational programs for children with dyslexia.

* Corresponding author: Bahman Akbari, Professor, Department of Psychology, Rasht Branch, Islamic Azad University, Rasht, Iran.

E-mail: Bakbari44@yahoo.com

Tel: (+98) 1333423308

2476-5740/ (C) 2021 The Authors. This is an open access article under the CC BY-NC-ND license

(https://creativecommons.org/licenses/by-nc-nd/4.0/). 


\section{Extended Abstract}

\section{Introduction}

Learning disability is a general term that refers to a heterogeneous group of disorders that occurs in the form of significant difficulties in acquiring and using listening, speaking, reading, writing, reasoning, or mathematical abilities. These disorders are internal and their possible cause is central nervous system dysfunctions (1). The most common learning disability is dyslexia, which is the most important cause of failure in school (2) and refers to a pattern of learning difficulties including difficulties incorrect or fluent word recognition, decoding, and spelling (6). Children with dyslexia have low scores on verbal tasks, extending number practice, word recall, central executive dysfunction, and problems with visuospatial information processing (8-11). They have poorer academic performance than their normal peers $(15,16)$. These factors can be caused by low self-esteem in these children. Low self-esteem leads to a negative attitude and increasing motivation to reading.

In most research, attitudes to reading are recently noted as a part of a wider structure, known as reading motivation. Researchers repeatedly found that high motivation and positive attitudes are associated with higher success in repetitive reading and studying (15). Mihandoost, Elias, Sharifah, and Mahmud (19) showed that students with dyslexia have negative attitudes and lower motivation than their peers. Another study (15) also indicated that students with dyslexia show weak academic performance and negative self-concept than their peers. They find reading is less enjoyable and rewarding than for them.

There are several treatments for children with dyslexia, including sensory-motor integration therapy (SMIT). The sensory integration theory states the relationship between defects in sensory processing, bodily sensations, and difficulties in learning motor skills (20).

Various studies indicate the SMIT is an effective treatment for the performance of children with specific learning disorders (21-24). For instance, a research has shown that sensory integration treatment is a promising way to improve the academic scores of children with learning disabilities (25). Given the catastrophic effects of learning disabilities on children and the heavy imposed damage on educational institutions, it would be crucial to use an appropriate intervention program. The strength of the present research was the simultaneous focus on the child and the parent. Therefore, The purpose of this study was to investigate the effect of a multidimensional intervention program (Sensory-Motor Integration Training for Child and Parent) on reading attitudes and performance of students with dyslexia.

\section{Method}

This was designed as a quasi-experimental study pre-test-posttest with a control group. The statistical population included students with dyslexia referred to educational and rehabilitation centers of specific learning problems in Rasht city in the 20192020 academic year. A sample of 40 people was selected by the convenience sampling method. The sample was selected according to the inclusion criteria (age range of 8 to 11, lack of comorbid disabilities, obtaining a score of at least 1.5 standard deviations below the mean in the Reading and Dyslexia test of Kormi Nouri and Moradi (Nema), IQ between 85 and 115, attending public schools and having significantly lower scores on Reading attitudes and performance test) and exclusion criteria (being absent for more than two sessions in intervention sessions and lack of written informed consent of parents). After obtaining the necessary permissions and the informed consent of the participants, they were randomly assigned to the experimental and control groups (20 people in each group).The participants initialy were given the $4^{\text {th }}$ edition of the Wechsler Children's Intelligence Scale (26), the Reading Attitude Scale, and the Reading and Dyslexia test (Nema) (31) as a pre-test; after eight 60-minutes-sessions of treatment for the experimental group (child and mother), they was assessed as the post-tested. It should be noted that the psychometric properties of all questionnaires are approved in Iran. Data were analyzed by one-way and multivariate analysis of covariance in the SPSS 22 software environment.

\section{Results}

Table 1 show descriptive statistics of reading attitudes and performance variables of the two experimental and control groups; it also indicates the Shapiro-Wilk test to determine the normality of the distribution of variables in the groups.

Table 1: Descriptive statistics of reading attitudes and performance

\begin{tabular}{ccccccc}
\hline Variables & Phase & Group & Mean & SD & SH-W & P \\
\hline Reading attitudes & pretest & Experiment & 42.75 & 4.541 & 0.953 & 0.398 \\
& & Control & 43.25 & 3.851 & 0.97 & 0.745 \\
& posttest & Experiment & 5725 & 4.153 & 0.971 \\
Reading performance & & Control & 43.02 & 4.039 & 0.955 & 0.77 \\
& pretest & Experiment & 73.69 & 7.758 & 0.979 & 0.459 \\
& & Control & 72.95 & 8.159 & 0.914 & 0.097 \\
& posttest & Experiment & 87.10 & 7.988 & 0.974 & 0.828 \\
& & Control & 73.6 & 9.588 & 0.922 & 0.099 \\
\hline
\end{tabular}




\section{Quarterly Journal of Child Mental Health}

Vol. 8, No. 2, Summer 2021

According to the results of table 1, the normality of distribution of the variables is assumpted. Before performing the analysis reports, all statistical assumptions were tested. The results of one-way analysis of covariance to investigate the differences between the experimental and control groups in the pre-test and post-test total score of the reading attitudes showed that there is a significant difference between the two groups in this variable $\left(F_{1,37}=1028.183, P=0.001\right)$. Also, the effect size of 0.965 shows that this difference was large in the population. The results of multivariate analysis of covariance of reading attitudes subscales show that F-statistic is significant for the subscales of out-of-school reading attitudes (488.862) and atthe-school-reading attitudes (549.634) at the level of 0.001 . These findings indicate that there is a significant difference between the experimental and control groups in these subscales $(\mathrm{P}<0.001)$. The results of the mean scores also show that the mean of the experimental group in all subscales of reading attitudes is higher than the mean of the control group in these subscales. The results of univariate analysis of covariance to examine the differences between the experimental and control groups in the pre-test and post-test total score of the reading performance show that there was a significant difference between the two groups in this variable $(\mathrm{F}=77.738, \mathrm{P}=0.001)$. Also, the effect size of 0.737 shows that this difference is large in the population. The results of multivariate analysis of covariance of reading performance subscales shows that Fstatistic for the subscales of word reading $(\mathrm{F}=136.13)$, word chains reading $(\mathrm{F}=304.87)$, rhyming $(\mathrm{F}=57.164)$, picture naming $(\mathrm{F}=31.068)$, text comprehension $(\mathrm{F}=54.009)$, word comprehension $(\mathrm{F}=93.176)$, phoneme deletion $(\mathrm{F}=38.131)$, Non-words \& Pseudo-words Reading $\quad(\mathrm{F}=29.485)$, letter fluency $(\mathrm{F}=71.538)$ and the category fluency $(\mathrm{F}=49.16)$ is significant at the level of 0.001 . The results of the mean scores also show that the mean of the experimental group in all subscales of reading performance is higher than the mean of the control group in these subscales.

\section{Conclusion}

The present study sought to investigate the effect of a multidimensional intervention program (Sensory-Motor Integration Training for Child and Parent) on reading attitudes and performance of students with dyslexia. Accordingly, it is concluded that the intervention has significant effects on the reading attitude and performance of students with dyslexia based on the results. These results are consistent with the results of previous studies (21-24); however, no similar research was found on the effectiveness of sensory-motor integration training on reading attitudes of children with dyslexia. These findings indicate that the intervention was effective on higher brain functions, which are responsible for higher-level processes such as attention and improves children's environmental sensitivity (24). The treatment of sensory-motor integration by engaging various senses in learning makes the task more attractive. Playing is desirable for children, and it could be an effective method of teaching for children. So using SMIT can be very attractive for children, and this will increase their motivation. In addition, the child feelings could be more acceptable and understanding by the parents' participation in child's learning. It also makes them eager to learn, because in this case, the child and the parents are both in the same side of the equation and the parents become more involved in the child's development.

One of the limitations of the present study was that it was determined to children with dyslexia as well as a specifier of learning disabilities. We suggest that future researchers perform the multidimensional intervention for children with different learning disabilities such as writing and mathemathic specifiers of learning disorders. In addition, due to time constraints, the Coronavirus diseases 2019 pandemic, and the closure of educational and rehabilitation centers of specific learning difficulties, it was not possible to conduct a follow-up course, so we suggest that in future research, the follow-up stage will be considered. It is also suggested that the education and rehabilitation centers of children with special learning disabilities should not be limited to the treatment of the child and should consider multi-dimensional therapies and interventions for the child, parents, and educators.

\section{Ethical Considerations}

Compliance with ethical guidelines: This research has been extracted from the doctoral dissertation of the first author, in the Islamic Azad University, Rasht Branch, on 2020/6/20, and the research design code is 950335932, with ethics IR. IAU. RASHT. TEC. 1399.093. its implementation license has been issued by the Department of Exceptional Education with the letter number 150/73 dated 2020/7/5. In this research, the ethical codes like obtaining the informed consent of the participants and confidentiality were considered by the authors.

Funding: The present study has conducted without any sponsoring from a specific organization.

Authors' contribution: This article is part of the first author's doctoral dissertation under the supervision of the second and third authors and the advice of the fourth author.

Conflict of interest: There is no conflict of interest for the authors in this study.

Acknowledgments: The authors of the article consider it necessary to appreciate all participants in the research. 


\title{
تأثير برنامه مداخلهاى جندوجهى (آموزش يكيارجگى حسى - حر كتى در سطح كودك و والدين) بر نكرش و عملكرد خواندن دانش آموزان نارساخوان
}

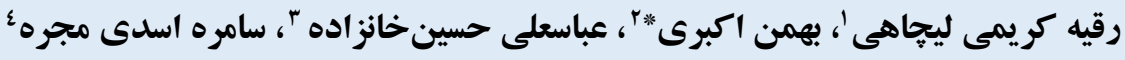

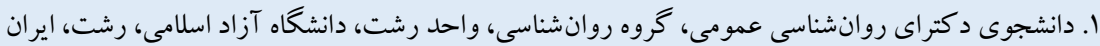

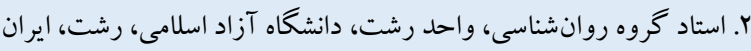

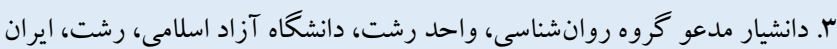

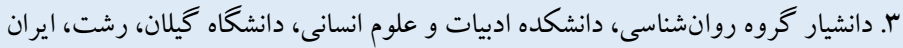

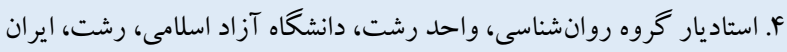

زمينه و هدف: نخر ش و عملكرد خو اندن دانش آموزان با نارساخوانى مى تواند نقش مهمى در موفقيت يا شكسـت در عملكرد تحصيلى

كليدوازهها:

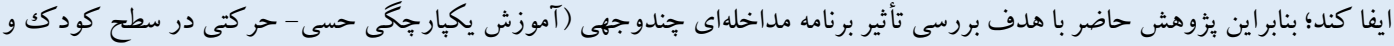

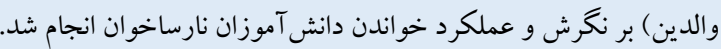

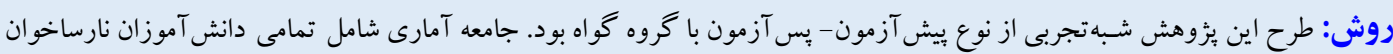

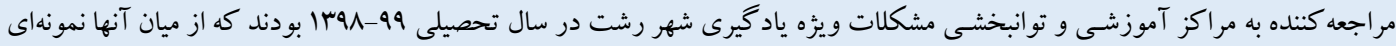

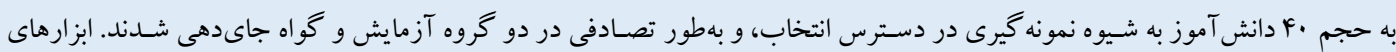

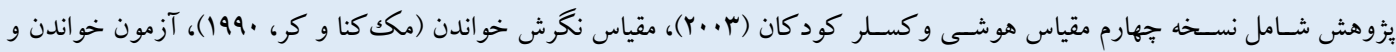

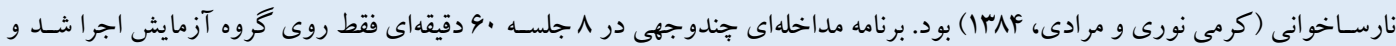

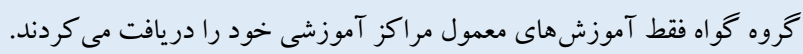

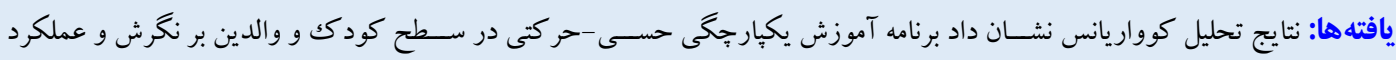

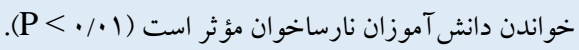

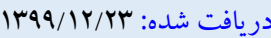

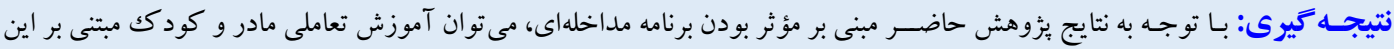

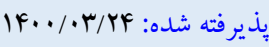

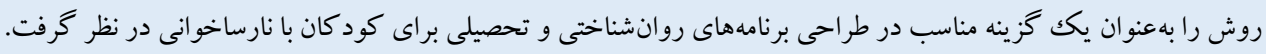


مركزى، و مشكلات در بردازش اطلاعات ديدارى- فضـايى دارند (ي -

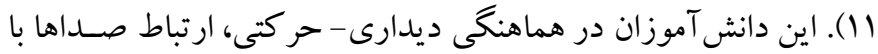

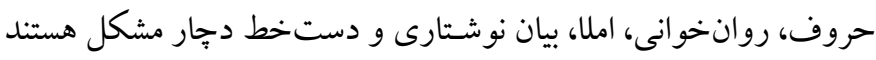

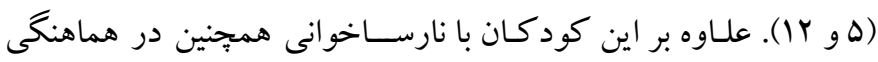

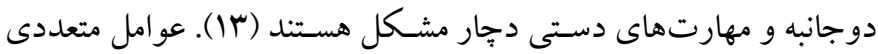
در شـكل گيرى اختلال خواندن نقش دارند كه از آن جمله مىتوان به به به عو امل زنتيكى، عصب ششناختى، محيطى، و همجنين عوامل شناختى اشاره

كرد (If)

شـواهد تجربى اهميت هر دو حوزه شـناختى و عاطفى را در توضسيح

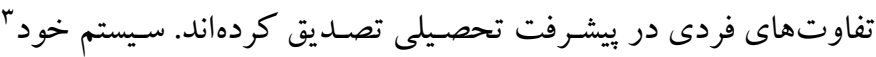

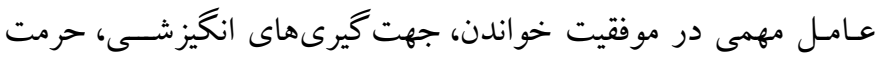

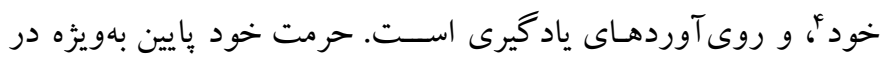

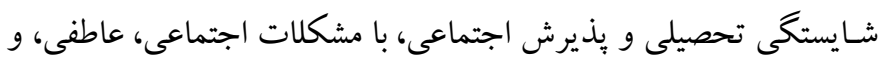

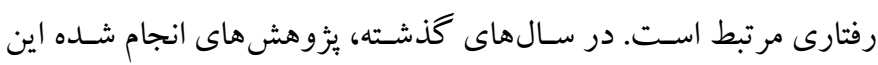

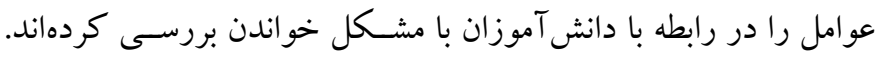
كود كان نارسـاخوان نسبت به همسـالان بهنجار خود از نظر تحصسيلى، از

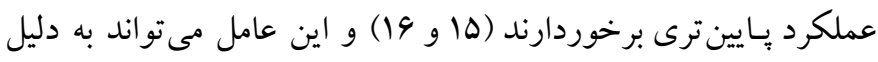

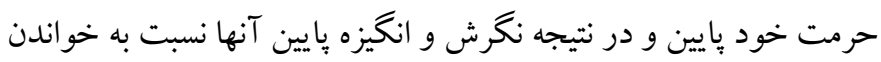

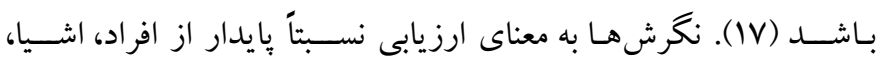

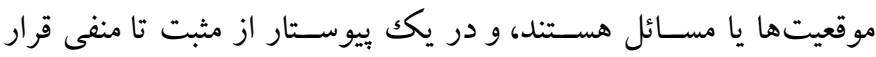

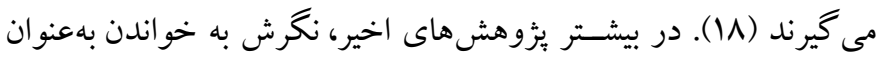

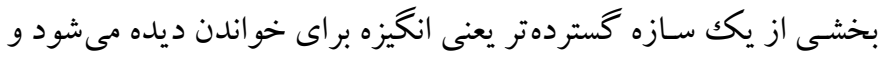

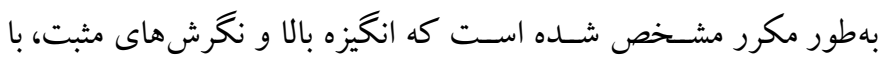

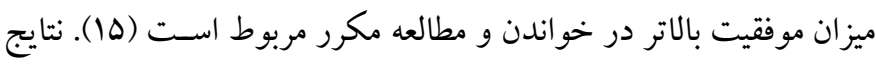

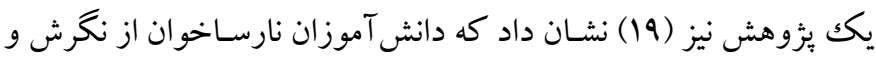

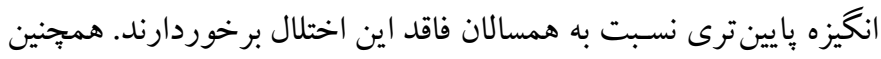

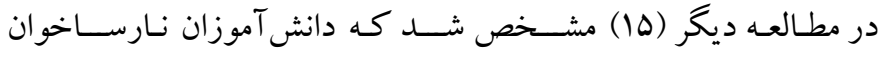
خودينداشت تحصيلى بايين ترى نسبت به همسالان خود نشان مى دهند و

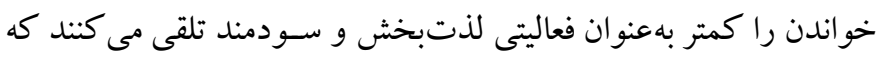

$$
\text { سبب تحول و ييشرفت فرد مىشود. }
$$

3. Self system

4. Seld esteem
مقلمهه

كمتوانىهاى يادكيرى'، اصـطلاح كلى اسـت كه به گروهى ناهمخن از

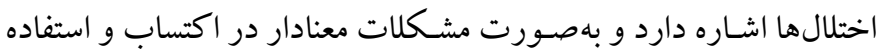

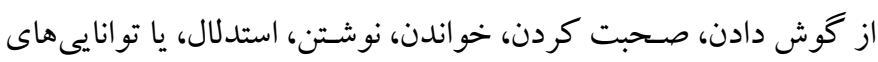
رياضسى بروز مى كند. اين اختلالها درونى بوده و فرض بر اين اسـت كه كه ناشى از نارسا كنش ورى در سيستم اعصاب مر كزى هستند و ممكن است

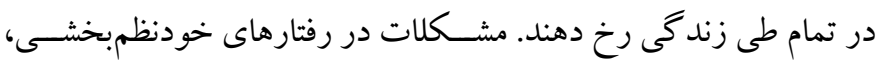

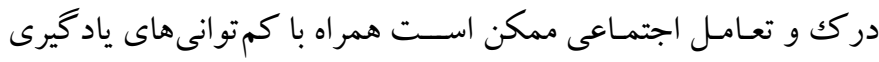

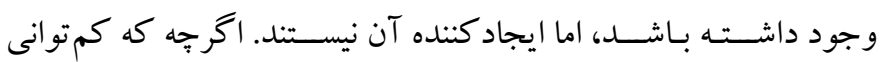
ياد گيرى ممكن است همزمان با سـاير كم توانىها (مانند آسيب حسى دهى،

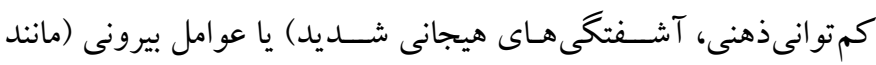

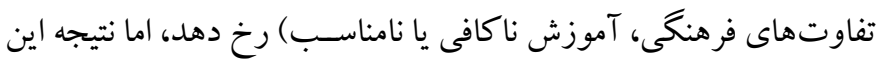

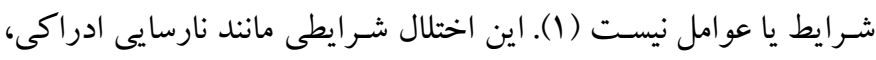

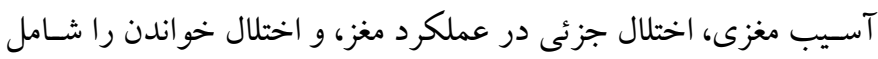

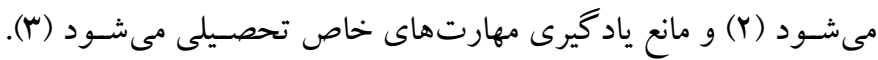

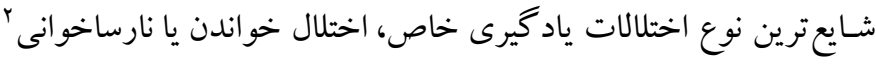

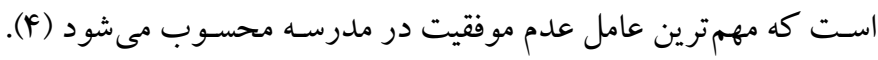

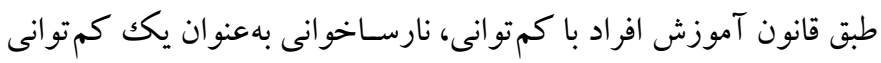

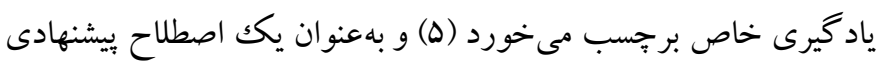

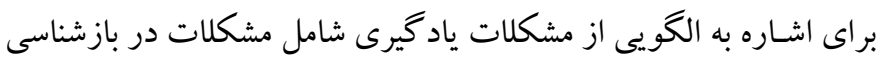
صحيح يا روان كلمه، رمز گشايى ضعيف و توانايى ضعيف هجى كردن

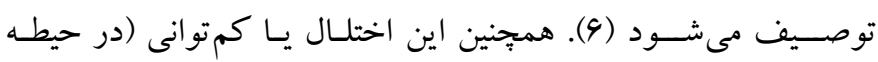

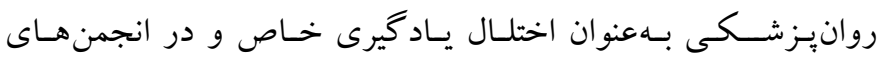

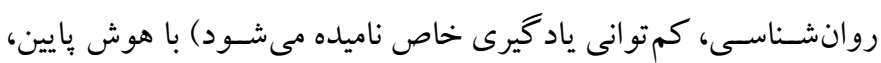

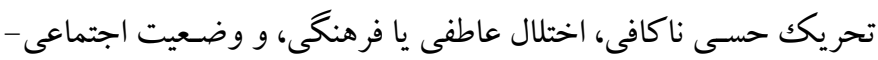
اقتصادى نامناسب مرتبط نيست (V) بررسى يزوهش هاى انجام شده در حوزه اختلال خواندن حاكى از آن

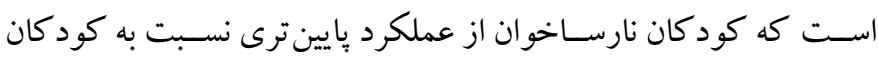

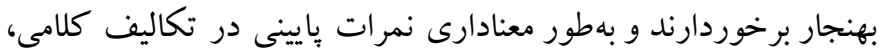

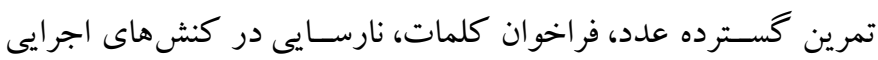

1. Learning disabilities

2. Dyslexia 
نمرات بايين معنادار در آزمون نخرش و عملكرد خو اندن، و رضسايت

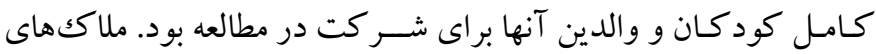

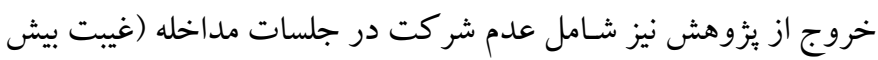
از r جلسه) و عدم رضايت كتبى والدين بود.

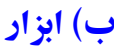
() نسخه جهارم مقياس هوشى وكسلر كودكان' (r.r.r): ويرايش جهارم مقياس هوش و كسـلر كودكان توسط و كسـلر در سـال ب..r ساخته شد. اين نسخهة، قابليت سـنجش هوش كود كان در دامنه سـى 9 تا 19 سـال و

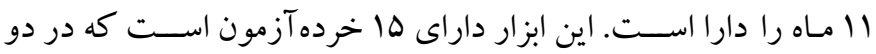

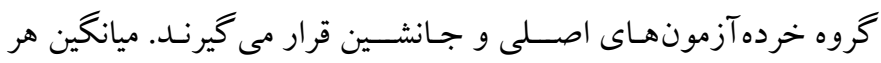

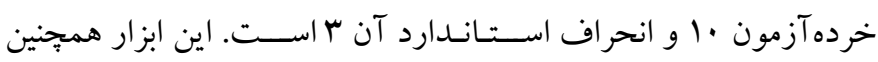

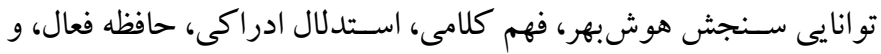

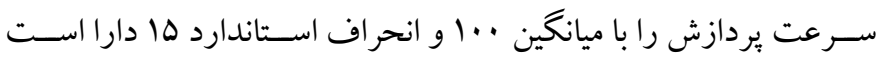
(Yצ). براى بررسى روايى اين آزمون از روشهاى مختلفى مانند محاسبه

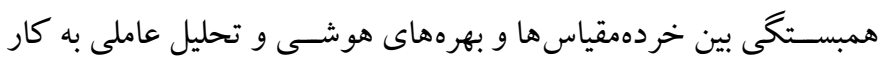
برده شد كه هر دو روش مؤيد روايى مناسب مقياس است. اين مقياس در بردي

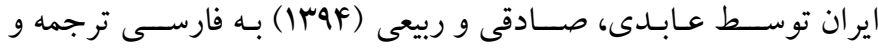
هنجاريابى شده است كه بيشترين و كمترين ضريب بايايى زيرمقياس ها با

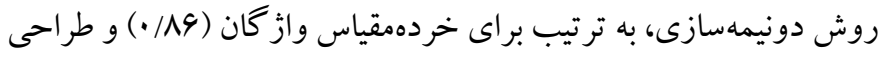

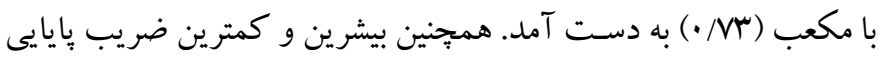

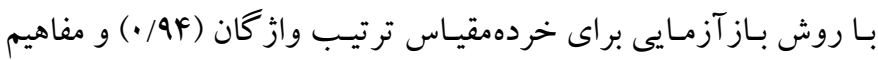

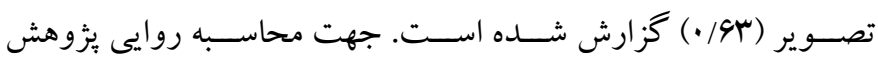
همبسـتخى نمرات ·ب نفر بـا آزمون ريون و مقيـاس وكسـلر كودكـان

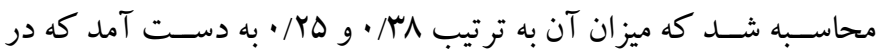

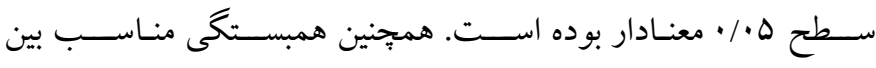

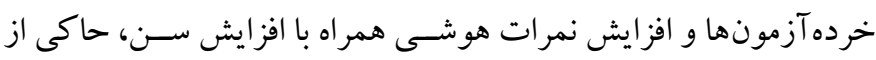
روايى مطلوب اين ابزار در ايران است (YV)

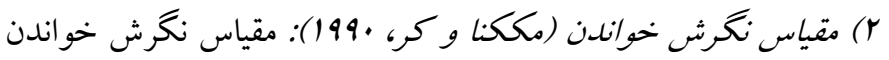
در سـال •199 توسط مككنا و كر (YN) ساخته شد. اين مقياس دار ایى دو

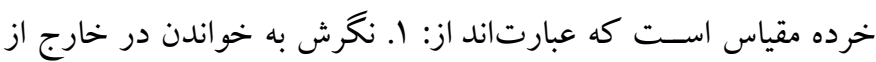

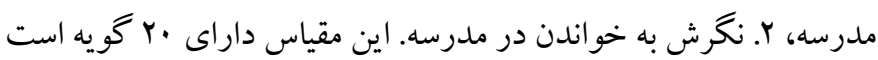

براى درمان كود كان نارسـاخوان، روى آوردهاى مختلفى وجود دارد

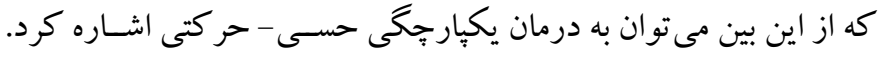

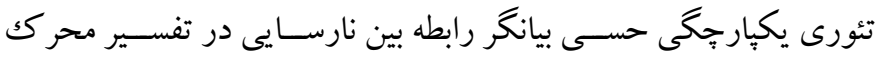

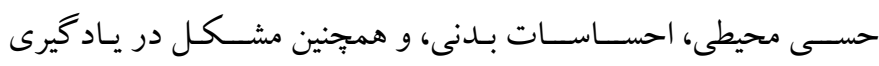

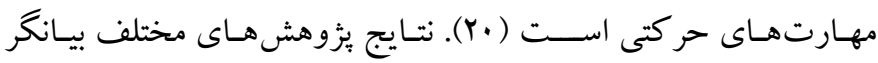

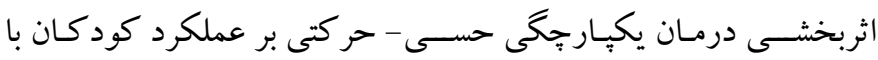

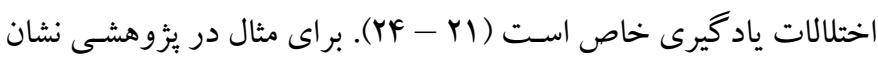

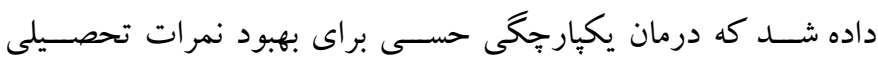

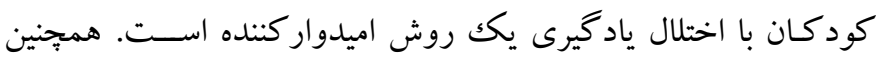

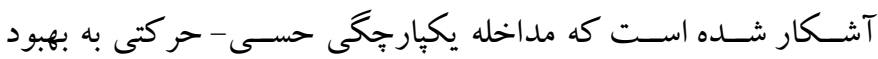

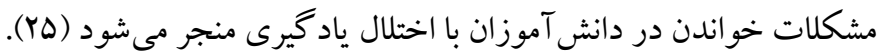

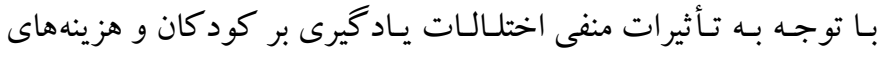

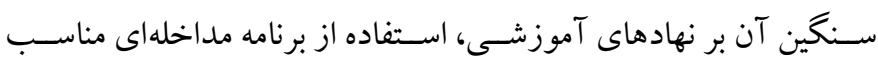

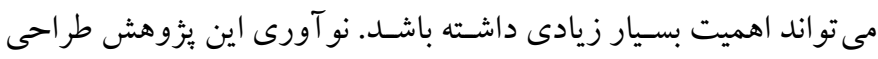

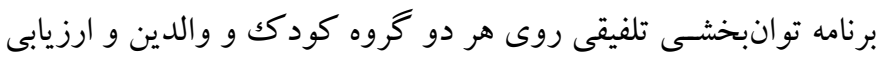

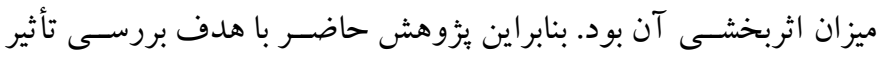

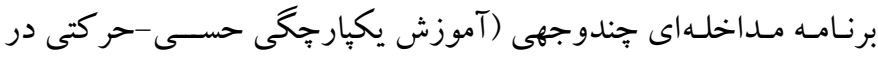

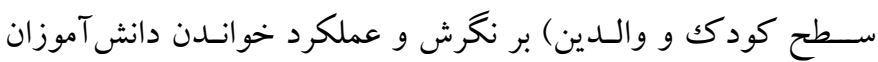
نارساخوان انجام شد.

روش الف) طرح يزوهش و شر كت كنند كان: طرح اين يزوهش شـبه تجربى

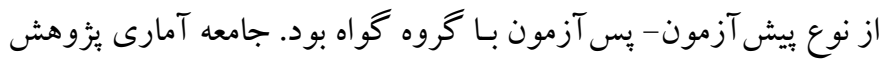

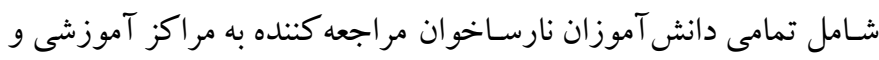

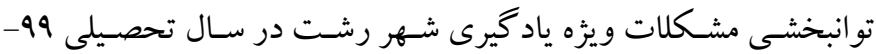

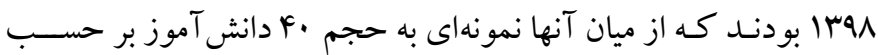

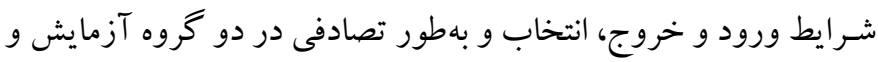
كواه جاىدهى شـدند. ملاككهاى ورود به ئزوهش شـامل داشتن ضريب

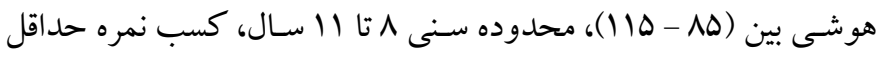

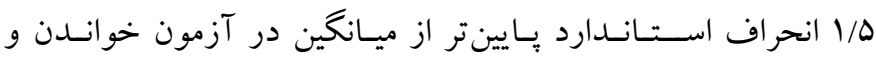
نارساخوانى نما، نداشتن اختلال همبود، تحصيل در مدارس دولتى، داشتن 
زنجيرء كلمـات، در كك كلمـات، قـافيه، حـذف آواها، خو اندن كلمات

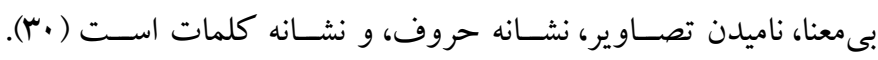

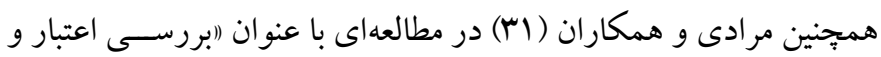

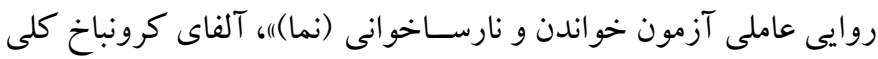

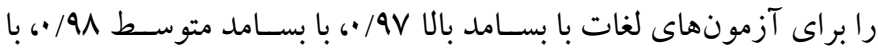

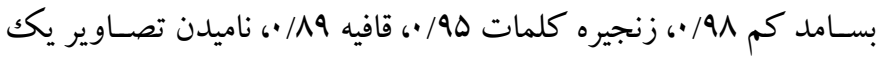

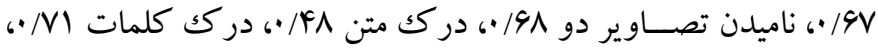

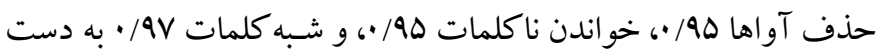

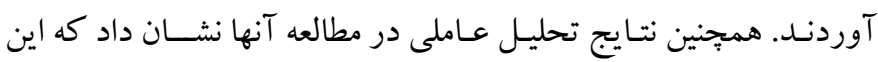
آزمون از دو عامل اصلى تشكيل مىشـود كه عامل يكم به ترتيب شامل

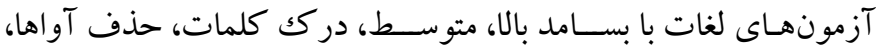
خو اندن ناكلمات، و شـبه كلمات؛ و عامل دوم شـامل آزمونهاى زنجيره

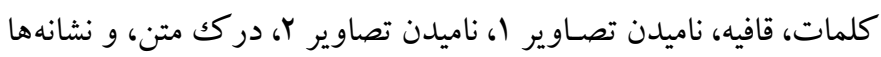
است.

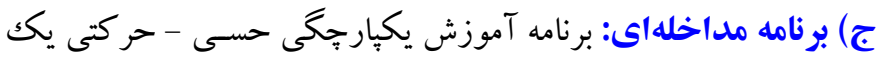

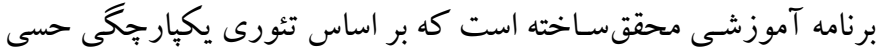

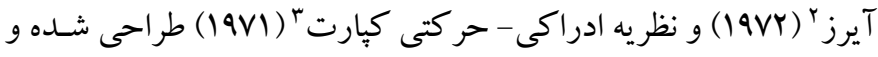

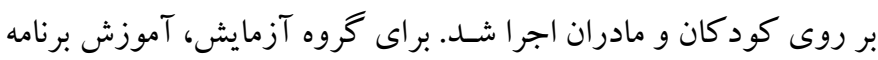

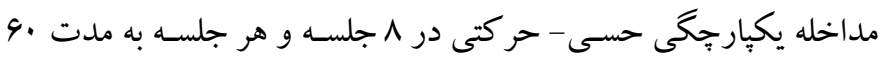
دقيقه (هفتهاى Y جلسـه) بدون در نظر گرفتن ييش آزمون و يس آزمون

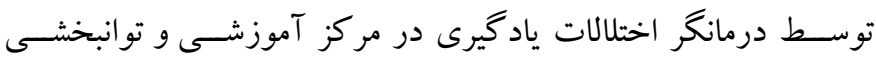
مشـكلات ويزه يادگيرى به دانش آموزان نارسـاخوان و نيز مادران آنها

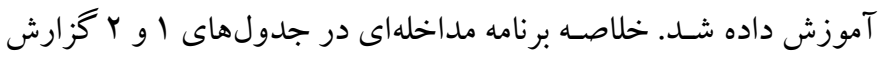

كه هر گويه شامل جمله سادهاى درباره خواندن است كه دانش آموزان با

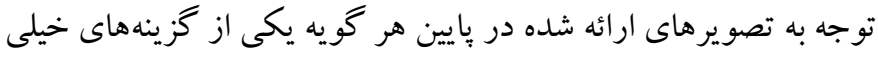

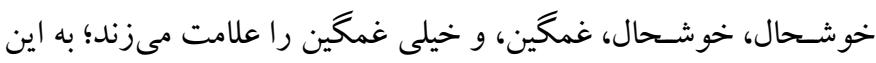

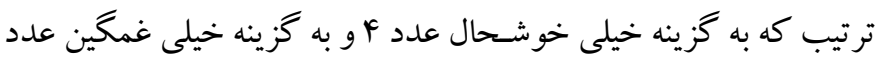

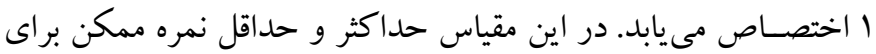
كل مقياس به ترتيب •م و •r و حداكثر و حداقل نمره ممكن براى هر

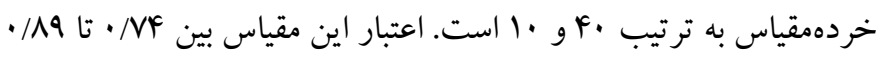

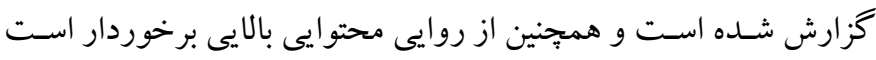

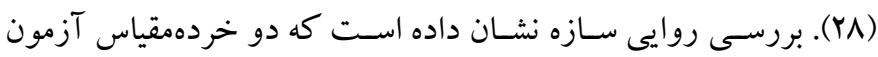

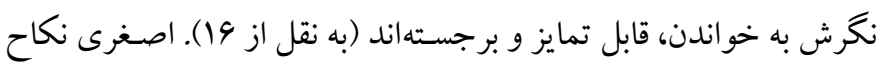
(Yq) در بزوهش خود براى بررسسى آن كه اين ابزار دو حيطه خواندن

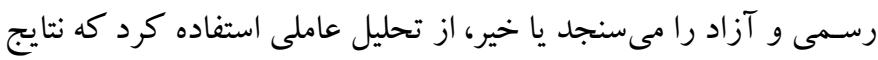
به دست آمده حاكى از روايى عاملى مطلوب اين ابزار بوده است.

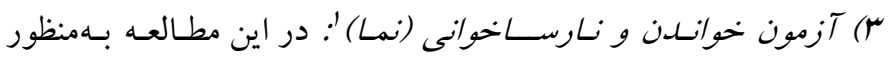

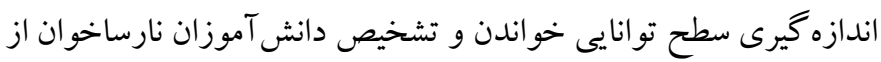
آزمون خواندن و نارسـاخوانى نما كه توسـط كرمى نورى و مرادى در

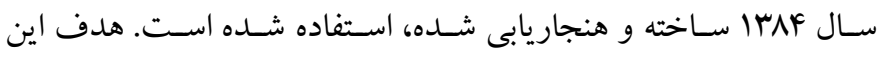
آزمون بررسى ميزان توانايى خو اندن دانش آموزان بهنجار دختر و يسر در هرد

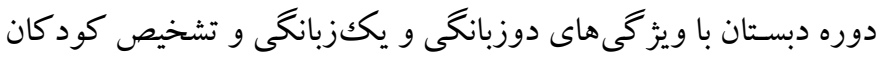

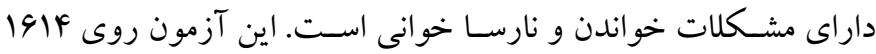
دانش آموز در بنج بايه تحصسيلى ابتدايى هنجاريابى شــده اسـت و اعتبار

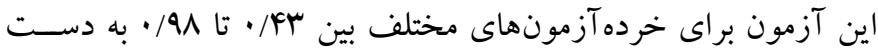

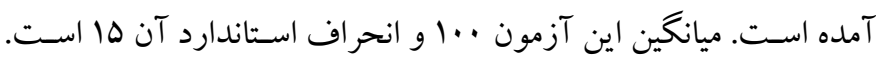
اين آزمون شـامل · ا خردهمقياس خواندن كلمات، دركك خو اندن متن، 
جدول 1: جلسات برنامه آموزش يكيارجگى حسى - حركتى در سطح آموزش به كودكى

\begin{tabular}{|c|c|}
\hline روش اجرا & 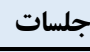 \\
\hline إل به جلو و عقب رفتن و بهطور همزمان شمارش از اتا · او برعكس & يكم \\
\hline ايستادن روى يكك ٍٍ و بهطور همزمان به خاطر سيردن جند شكل به ترتيب و برعكس & دوم \\
\hline تقليد راه رفتن حيوانات و بهطور همزمان تشخيص يكك واج تكرارى از ميان جندين واج و يا تشخيص يك كلمه تكرارى از ميان جندين كلمه - ايجاد طرحهايى روى كاغذ با استفاده از & 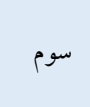 \\
\hline ايستادن روى تخته تعادل و بهطور همزمان تشخيص يكك واج متفاوت و يا يكى كلمه متفاوت از ميان هندين واج و يا جندين كلمه تكرارى - بريدن اشكال و جسباندن آنها روى يكك مقوا & 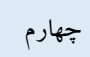 \\
\hline لىلى كردن و بهطور همزمان تشخيص كلمات هم آغاز و هميايان، نخ كردن مهرههاى رديف شونده & ينجم \\
\hline خرخيدن به دور خود و بهطور همزمان ارائه جفت كلمات متداعى و جفت كلمات بىربط، مجاله كردن كاغذ و درست كردن توبهاى كاغذى & ششم \\
\hline 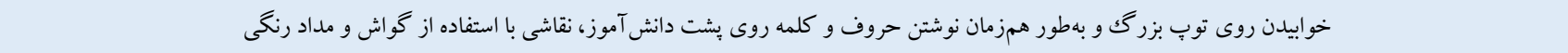 & 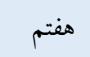 \\
\hline يرش روى كارت كلمات و جملات - مرتب كردن كلمات در همريخته بهصورت يك جمله كامل، رسم كردن بعضى علائم روى كف دست دانش آموز و ترسيم آن روى كاغذ توسط & هشتم \\
\hline
\end{tabular}

جدول ז: برنامه مداخله يكيارجگى حسى - حر كتى در سطح آموزش به والدين

روش اجرا

آشنايى والدين با انواع مشكلات حسى و علائم آن بمنظور برجسته كردن لزوم جنين برنامهاى آموزشى و ايجاد انكيزه و جلب همكارى آنها

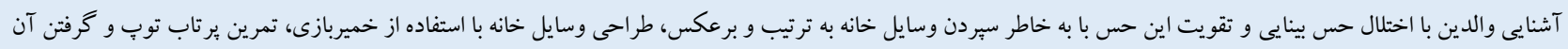

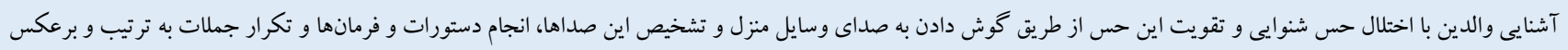

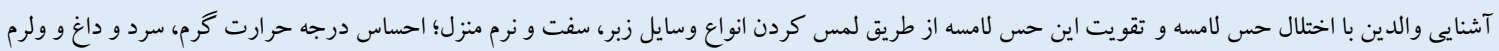

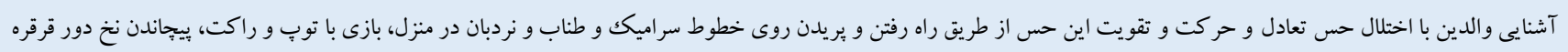

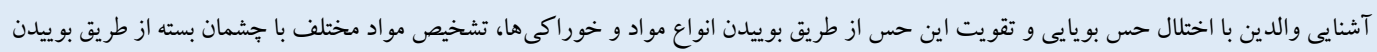

ينجمب

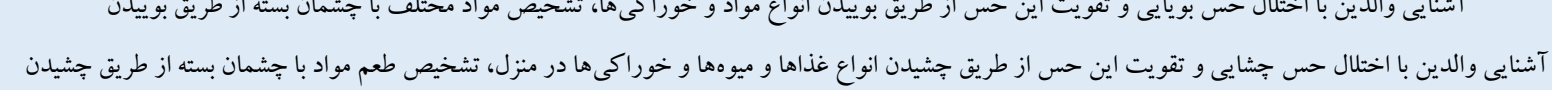

بررسى نحوه تعاملات والدين با كودكى و بررسى اجمالى مسائل و موضوعات مطرح شده در جلسات ييشين، شرح عوامل بازدارنده تغييرات و اصلاحات ايجاد شده، و ارائه راهكارهايى جهت

حفظ تغييرات مذكور

والدين و كود كان در بازه زمانى يكسـان و در مراكز اختلالات يادگيرى

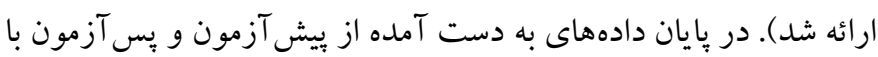

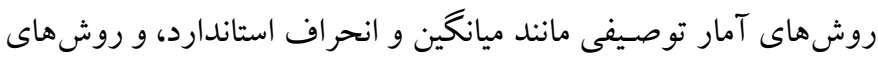

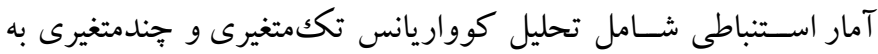
كمك نرمافزار آمارى SPSS

\section{يافته ها}

ميانگين و انحراف اسـتاندارد نمرات بيش آزمون - بِ آزمون متغير هاى

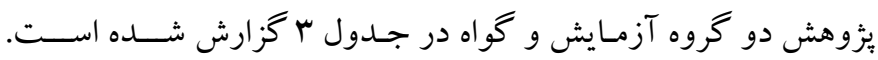

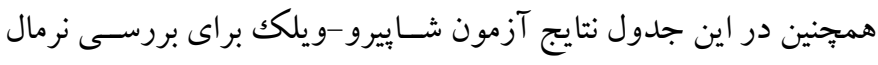
بودن توزيع متغيرها در گرووها گزارش شده است.
د) روش اجرا: بعد از كسب مجوزهاى لازم و مراجعه به مراكز آموزشى

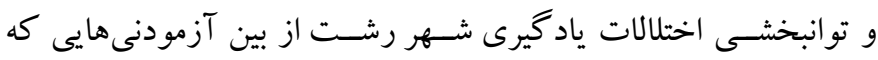

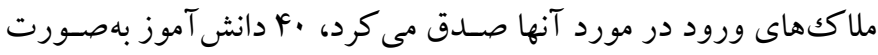
نمونه گيرى در دسترس انتخاب و بهطور تصادفى در دو گروه آزمايشى و

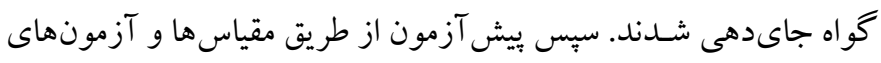

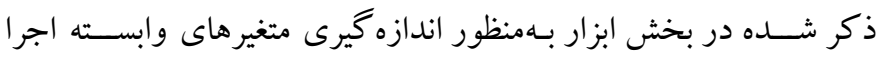

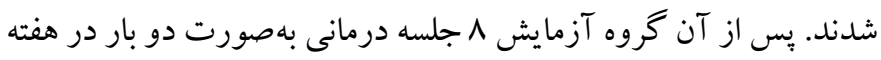

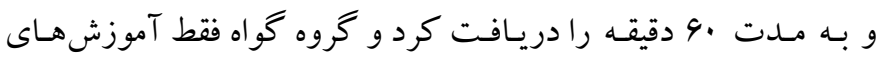
معمول مراكز را دريـافت كرده بود. بعـد از اتمـام جلســات درمـانى ترونى آزمودنىهـاى هر دو كروه مجــداً از لحساظ متغير وابسـتـهـ بـهـعنوان

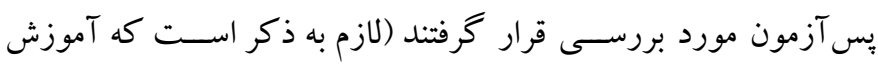


جدول rا: شاخصهاى توصيفى نمرات يشيش آزمون- يس آزمون در دو كروه آزمايش و كواه (تعداد: •ع)

\begin{tabular}{|c|c|c|c|c|c|c|}
\hline $\mathbf{P}$ & S-W & SD & M & كروه & وضعيت & متغير \\
\hline •/raA &.$/ 9 \Delta r$ & $F / \Delta F 1$ & Fr/ND & آزمايش & \multirow{2}{*}{ ييش آزمون } & \multirow{3}{*}{ نغخرش خواندن } \\
\hline - /Nes &.$/ 9 V$ & $r / A \Delta 1$ & $\kappa r / r \Delta$ & كواه & & \\
\hline$\cdot / \mathrm{VV}$ & $. / 9 \times 1$ & $F / D \Delta r$ & $\Delta V / r \Delta$ & كَّاه & ي" آزمون & \\
\hline . & ./ava & $\mathrm{V} / \mathrm{V} \Delta \Lambda$ & $v r / 99$ & آزمايش & \multirow{2}{*}{ ييش آزمون } & \multirow{3}{*}{ عملكرد خواندن } \\
\hline.$/ .92$ & $. / 9 / f$ & $1 / 109$ & Vr/aD & كواه & & \\
\hline - & / /aYY & V/AM & $\Delta V / 1$. & كَّواه & عِس آزمون & \\
\hline
\end{tabular}

P=•/lFV (F)

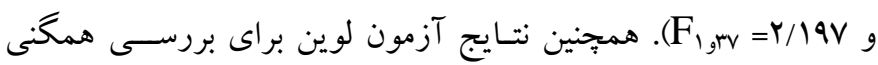

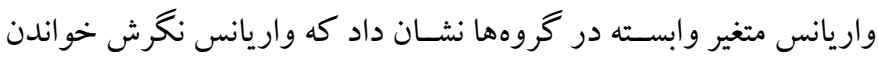

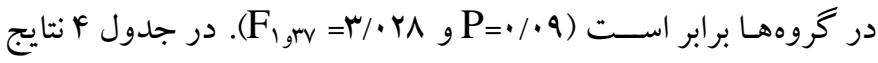

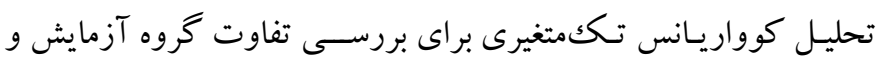

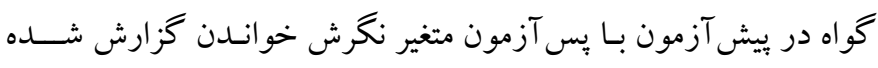

بـا توجـه بـهـ جـــول فوق نتـايج آزمون شــاييرو -ويلكك براى تمامى

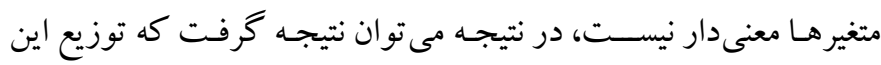

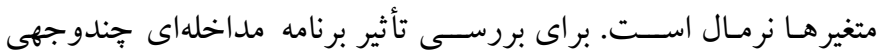

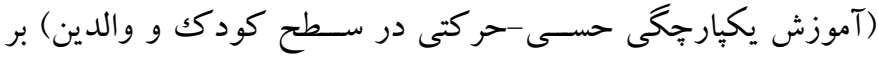

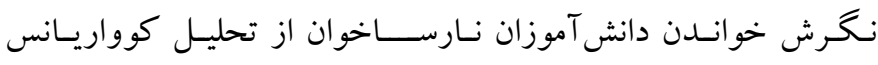

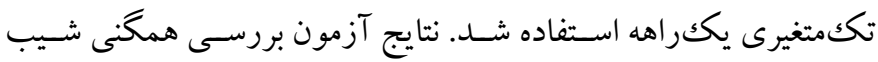

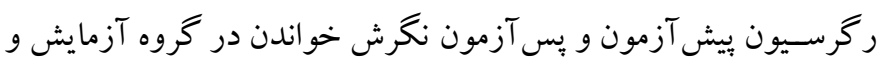

جدول ع: نتايج تحليل كوواريانس تكمتغيرى براى بررسى تفاوت كروه آزمايش و كواه در نكرش خواندن

\begin{tabular}{|c|c|c|c|c|c|c|}
\hline اندازه اثر & سطح معنادارى & $\mathbf{F}$ & ميانكين مجذورات & درجه آزادى & مجموع مجذورات & منبع تغييرات \\
\hline$\cdot / \mathrm{AV} \wedge$ &.$\cdot \cdot 1$ & rGV/TrV & $\Delta 9 \cdot / r \mid r$ & 1 & $\Delta G \cdot / r \mid r$ & ي يش آزمون \\
\hline \multirow[t]{2}{*}{.$/ 990$} &.$\cdot \cdot 1$ & $1 \cdot Y N / 1 \Lambda K$ & rIOr/gV. & 1 & $r \mid \Delta F / 9 V$. & عضويت گررهى \\
\hline & & & Y/.৭৭ & rv & VV/OHA & خطا \\
\hline
\end{tabular}

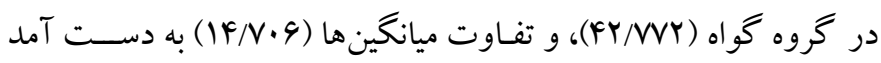

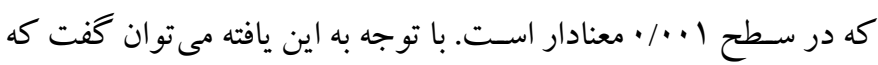

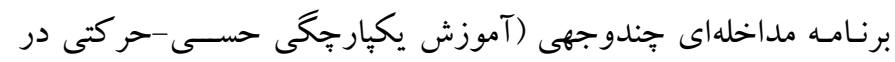

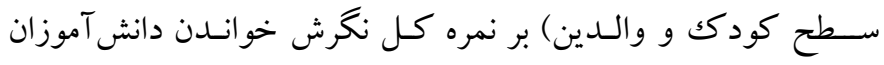
نارساخوان مؤثر است و موجب افزايش آن شده واست.

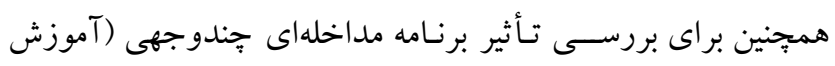

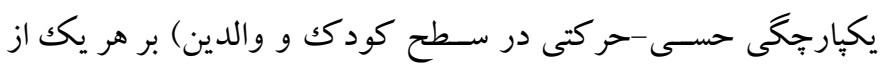

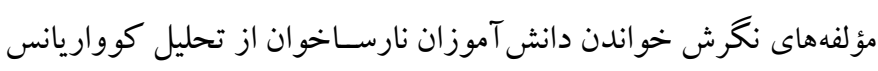

بـا توجـه بـه نتـايج جـدول F آمـاره F نكرش خو اندن در بـ آزمون

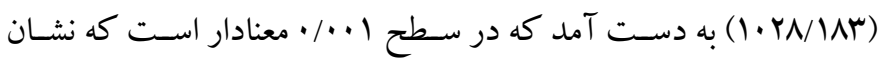
مى دهد بين دو گروه در نكرش خو اندن تفاوت معنادار وجود دارد. اندازه

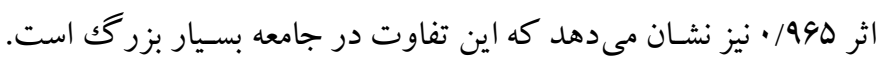

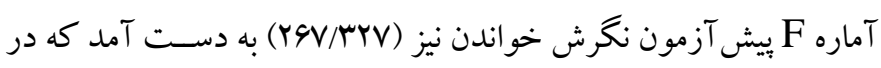

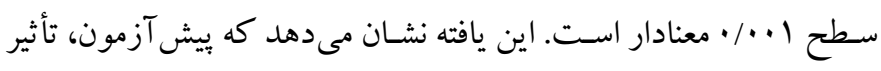

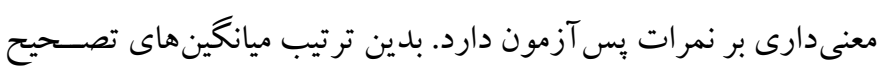

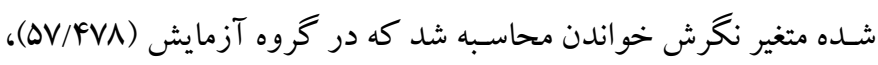


S

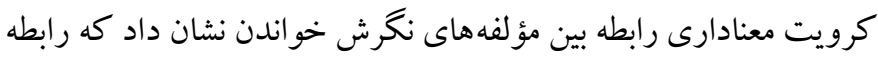

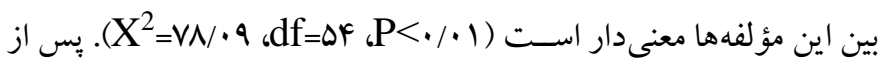
بررسى بيشفرض هاى تحليل كوواريانس خجندمتغيرى، نتايج آزمون نشان

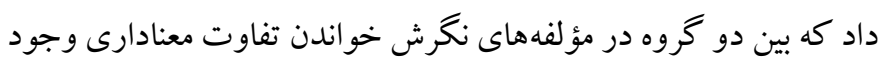

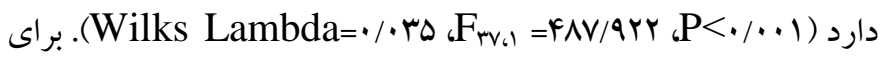
بررسـى اينكه گروه آزمايش و گواه در كدام يكك از مؤلفههاى نخرش

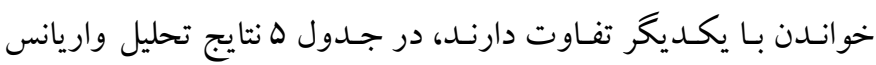
تككتغيرى گز ارش شده است.
جندمتغيرى يككر اهه اسـتفاده شـــ. نتايج آزمون بررسـى همخنى شـيب

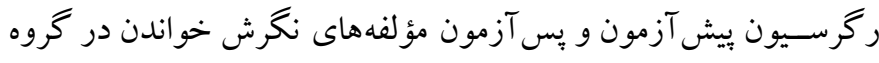

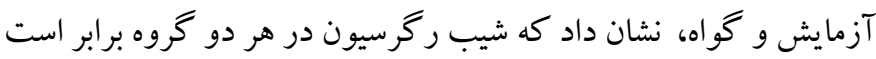

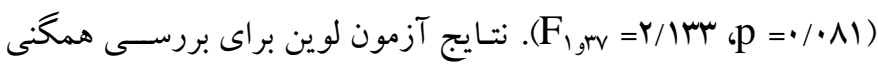

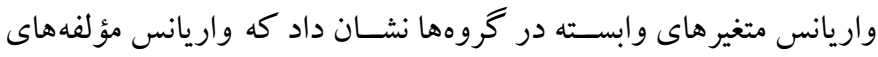
نخرش به خواندن در خارج از مدرسسه (F) نكرش به خو اندن در مدرسـه (F) برابر اسـت. نتايج آزمون باكس براى بررسى بروابرى ماتريس كوواريانس

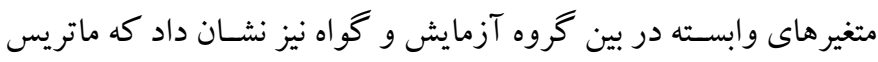

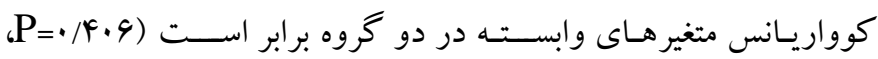

جدول 0: نتايج تحليل واريانس تفاوت تروه آزمايش و كواه در مؤلفههاى نكرش خواندن

\begin{tabular}{|c|c|c|c|c|c|c|c|}
\hline اندازه اثر & $\mathbf{P}$ & $\mathbf{F}$ & خطاى استاندارد & تفاوت ميانگين & ميانتين & كروه & شاخص مؤلفهها \\
\hline . $/ 941$ & $\% \cdot \cdot 1$ & FM/AGY & 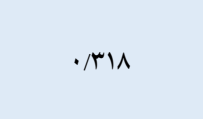 & $V / \cdot r V$ & $\begin{array}{l}r Q / .91 \\
r Y / . r Y\end{array}$ & كواه & نخرش به خو اندن در خارج از مدرسه \\
\hline.$/ 949$ & $\% \cdot \cdot 1$ & $\Delta F Q / q T F$ & - I & V/9AF & $\begin{array}{l}\text { YN/FIV } \\
r \cdot / N T r\end{array}$ & كواه & نخرش به خواندن در مدرسه \\
\hline
\end{tabular}

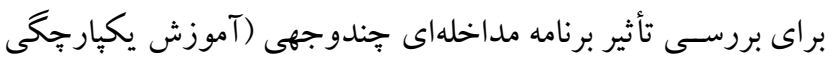

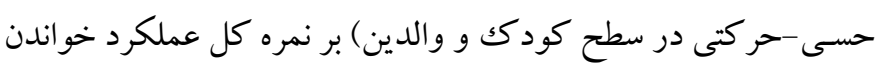

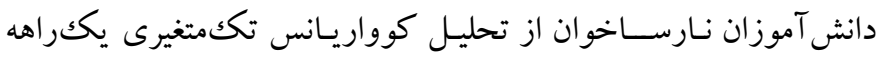

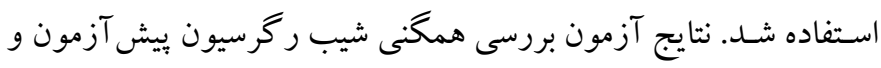

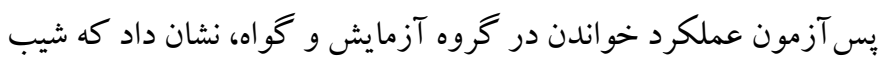

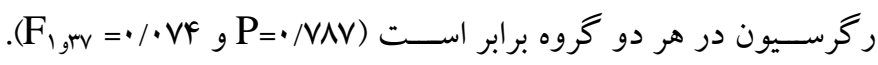

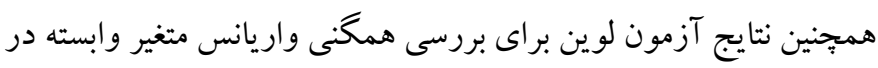

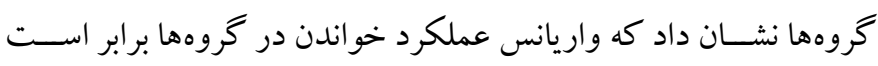

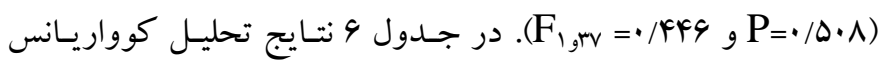

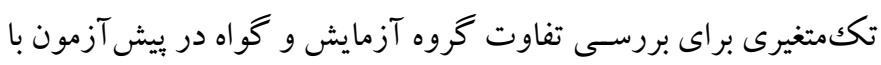

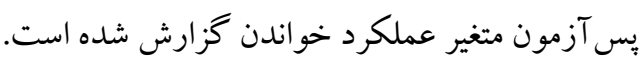

بـا توجسه بـه جــول ه آماره F براى مؤلفههاى نـخرش به خواندن در

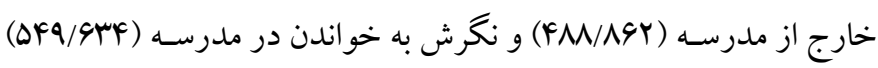

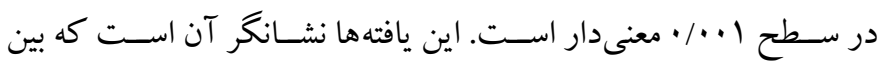

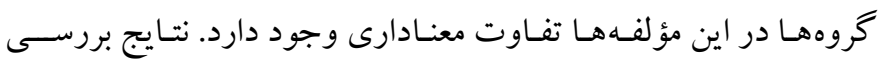

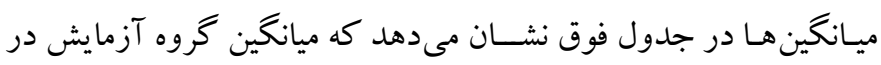

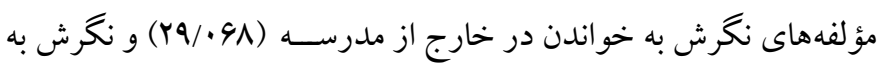

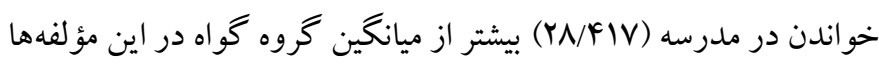

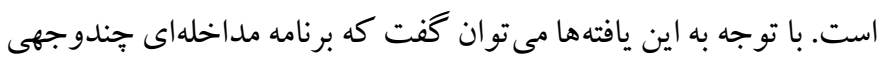

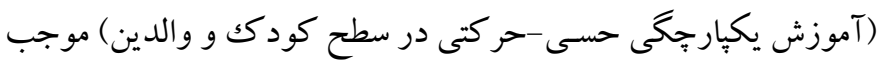

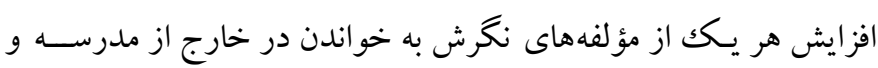
نخرش به خو اندن در مدرسه دانش آموزان نارساخوان شده است. 
جدول آ: نتايج تحليل كوواريانس تككمتغيرى براى بررسى تفاوت كروه آزمايش و كواه در عملكرد خواندن

\begin{tabular}{|c|c|c|c|c|c|c|}
\hline اندازه اثر & سطح معنىدارى & $\mathbf{F}$ & ميانكين مجذورات & درجه آزادى & مجموع مجذورات & منبع تغييرات \\
\hline $.19 \mathrm{VV}$ &.$/ .1$ & $1 . r / 94$ & $r / \Lambda \cdot / \Delta \Delta F$ & 1 & $r \mid \Lambda \cdot / \Delta \Delta F$ & يُش آزمون \\
\hline \multirow[t]{2}{*}{$\cdot / N r v$} &.$/ \cdot 1$ & $\mathrm{VV/GHA}$ & | & 1 & | & عضويت گروهى \\
\hline & & & $r Y / F T$ & rv & WN/DFG & خطا \\
\hline
\end{tabular}

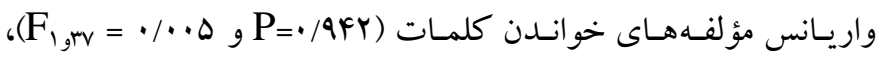
زنجيره كلمات (P) (

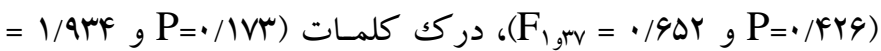

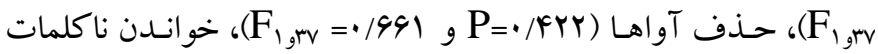

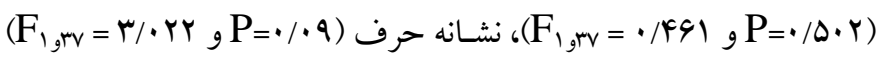

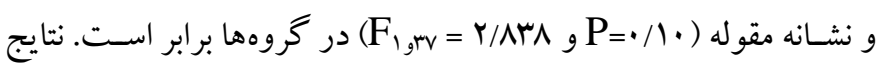
آزمون باكس براى بررسى برابرى ماتريس كوواريانس متغيرهاى وابسته

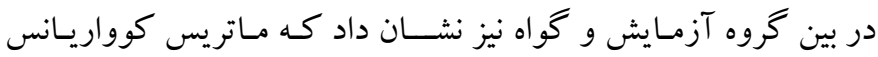

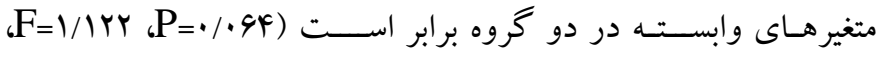

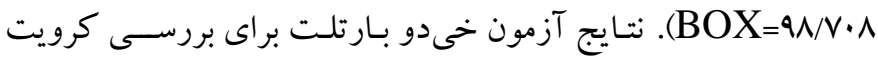

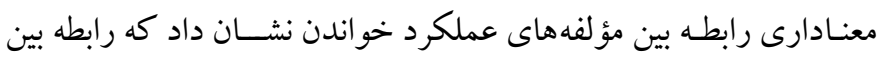

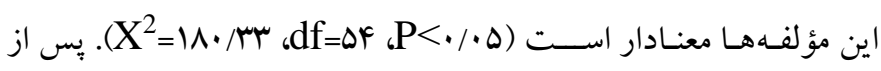
بررسى بيشفرض هاى تحليل كوواريانس جندمتغيرى، نتايج آزمون نشان

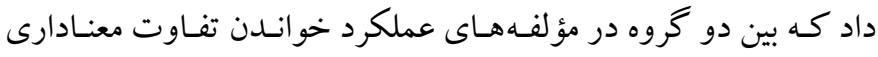

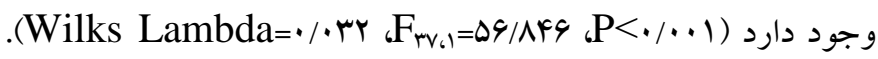

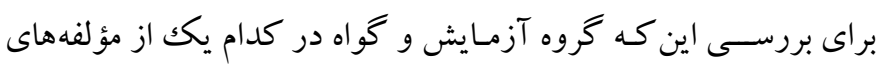

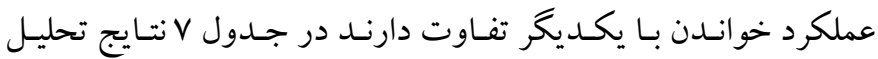
واريانس تككمتغيرى گزارش شده است.
بـا توجسه بـه نتـايج جـدول 9 آمـاره F عملكرد خوانسدن در بس آزمون (VV/GTNA) مىدهـد بين دو گروه در عملكرد خوانـدن تفـاوت معنـادار وجود دارد.

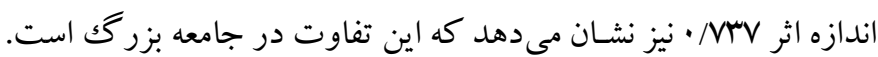

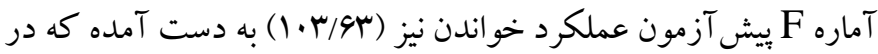

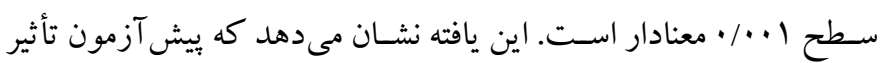

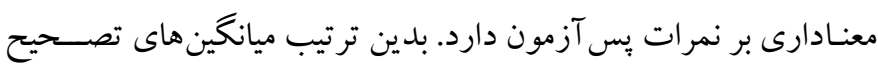

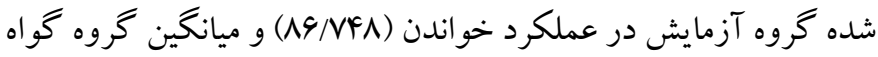

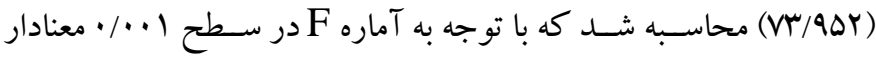

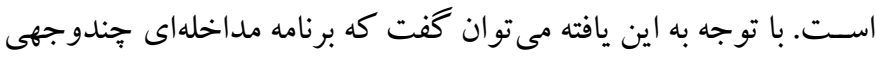

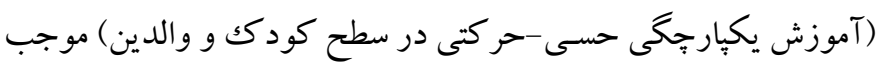
افز ايش عملكرد خو اندن دانش آموزان نارساخوان مى شودود.

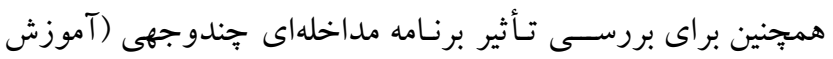

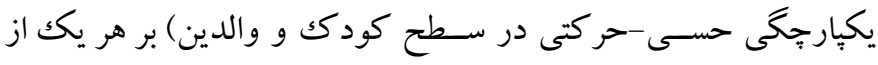

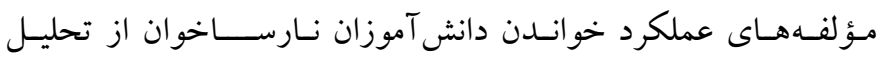

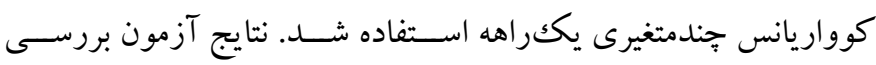

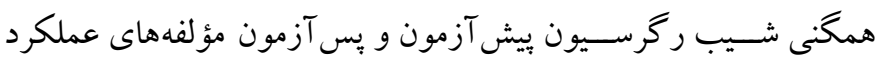

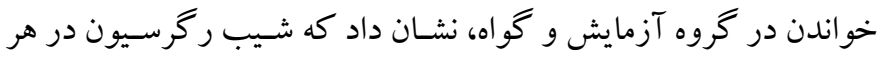

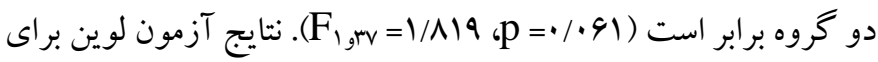

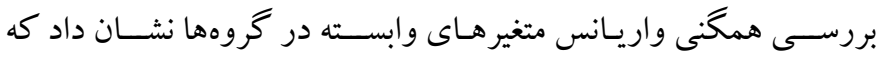

جدول Ү: نتايج تحليل واريانس تكمتغيرى تفاوت تروه آزمايش و كواه در مؤلفههاى عملكرد خواندن

\begin{tabular}{|c|c|c|c|c|c|c|c|}
\hline اندازه اثر & $\mathbf{P}$ & $\mathbf{F}$ & خطاى استاندارد & تفاوت ميانكين & ميانگين & كروه & شاخص مؤلفهها \\
\hline - /Ara &.$/ .1$ & Ira/1r & $\cdot / A \cdot \Delta$ & $9 /$ rqr & $\begin{array}{l}\Delta F / r q q \\
V F / q . F\end{array}$ & كو آزمايش & خواندن كلمات \\
\hline.$/ 919$ &.$/ .1$ & $r \cdot F / A V$ & . IAST & $10 / .99$ & $\begin{array}{l}\Delta . / 1 \wedge \Delta \\
r \Delta / 11 \Delta\end{array}$ & كواه & زنجيره كلمات \\
\hline $.19 \mathrm{VI}$ & $\% / \cdot 1$ & $\Delta V / / G q$ & $r / r \cdot V$ & $|V / F F|$ & $\begin{array}{l}Q \cdot / r Y \\
V Y / M\end{array}$ & كزاه & قافيه \\
\hline . /QYA &.$/ .1$ & $\mathrm{mI} / .91$ & 1/ArG & 1./rMr & $\Lambda 9 / Y 19$ & آزمايش & ناميدن تصاوير \\
\hline
\end{tabular}




\begin{tabular}{|c|c|c|c|c|c|c|c|}
\hline & & & & & $V \Delta / Q \Lambda A$ & كواه & \\
\hline .1909 & $\cdot / \cdot 1$ & $\Delta F / \cdot \cdot q$ & $r / V \cdot G$ & 19/AMV & $\begin{array}{l}1.1 / \mathrm{Al \Lambda} \\
\text { N1/arr }\end{array}$ & كوزاه & در كك متن \\
\hline -/V99 & $\cdot / \cdot 1$ & QY/IVQ & I/VAD & IV/rYq & $\begin{array}{l}\text { 11D/AGF } \\
\text { QN/GKG }\end{array}$ & كَزاه & درك كلمات \\
\hline$\cdot / \Delta \mathrm{VV}$ & $\cdot / \cdot 1$ & rN/IrI & $r / v V$ & rr/rVA & $\begin{array}{l}\text { KQ/YIF } \\
\text { ro/QYGQ }\end{array}$ & 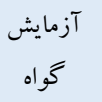 & حذف آواها \\
\hline •/DIr & $\%$ & YQ/FAD & $r / r \cdot r$ & IV/rar & $\begin{array}{l}\text { AV/VQV } \\
V \cdot / F \cdot r\end{array}$ & كَزاه & خو اندن نا كلمات \\
\hline$\cdot / 219$ & $\cdot / \cdot 1$ & VI/هTی & $r / r \Delta \Lambda$ & $19 / 9 F V$ & $\begin{array}{l}Q \Delta / T Y T \\
V \Delta / T V V\end{array}$ & كَزاه & نشانه حرف \\
\hline$\cdot 19 \mathrm{TV}$ & $\cdot / \cdot 1$ & $19 / 19$ & $Y / 9 \cdot Y$ & M/YKF & $\begin{array}{l}\text { M/DFV } \\
V \cdot / T \cdot r\end{array}$ & $\begin{array}{c}\text { آزمايش } \\
\text { كواه }\end{array}$ & نشانه مقوله \\
\hline
\end{tabular}

نكرش و عملكرد خواندن دانش آموزان نارسـاخو ان انجام شـــ. نتيجه اين

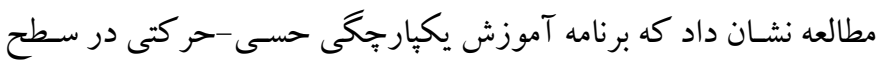

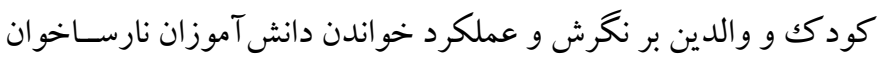

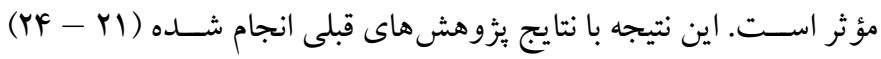

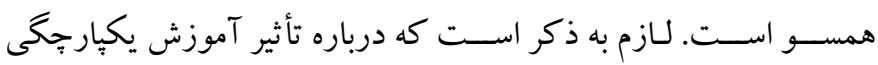

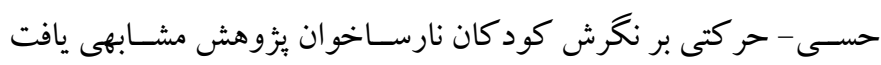

بهمنظور تبيين تأثير درمان يكِيارجگى حسـى - حر كتى بر عملكرد

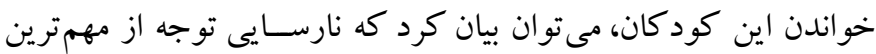

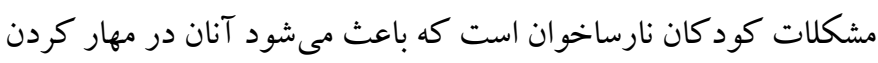
محر ككهاى مختلف و ياسـخكويى تنها با يكى از آن محر ككها، مشـكل

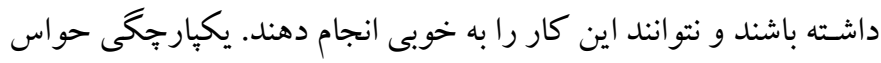

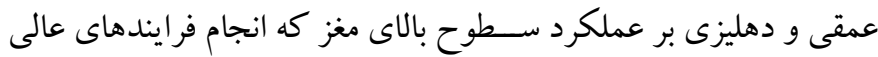

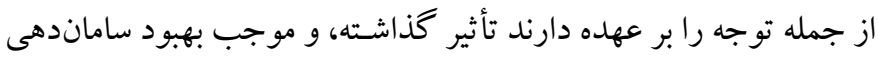

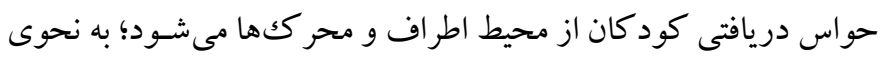

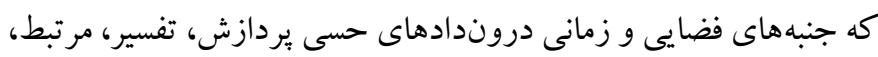
و تلفيق مى شــــــــــ و مغز اطلـاعات را انتخاب، تقويت، مهار، و مقايســهـ

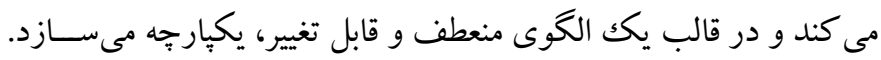

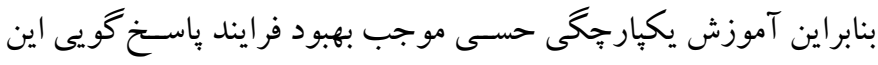

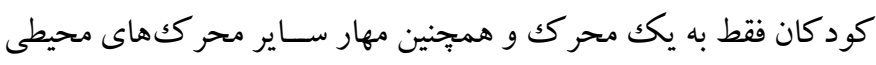

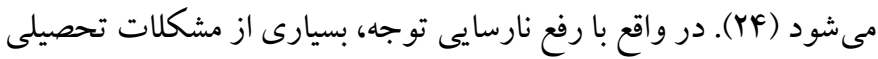

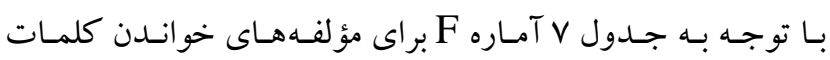

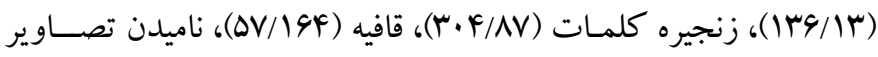

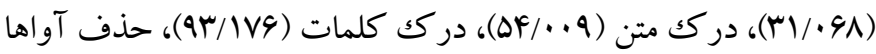

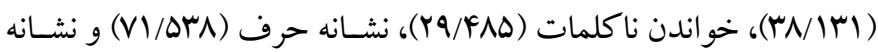

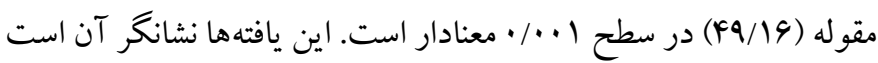

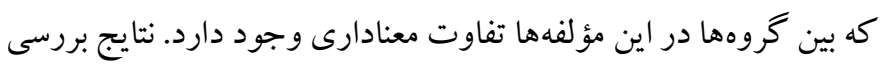

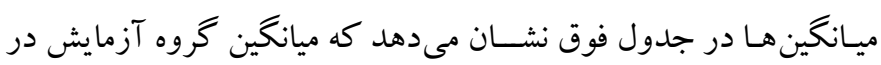

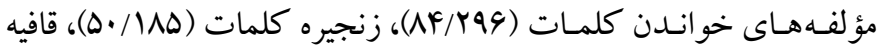

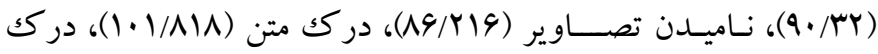

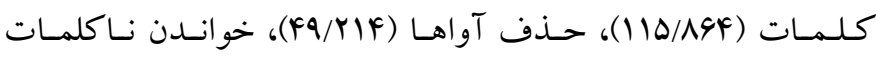
(AV/DQV)

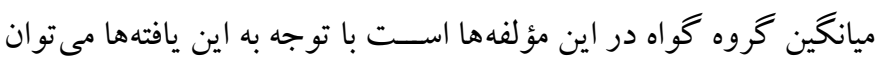

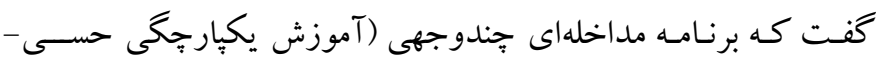

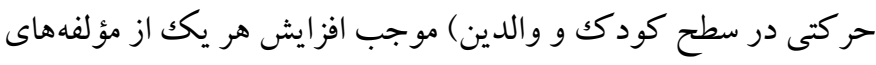

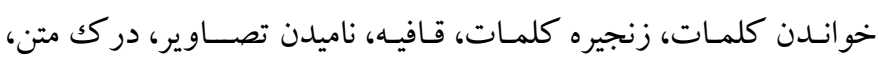
درك كلمـات، حذف آواها، خو اندن ناكلمات، نشــانه حرف، و نشـانه مقوله دانش آموزان نارساخوان مىشود.

\section{بحث و نتيجه كيرى}

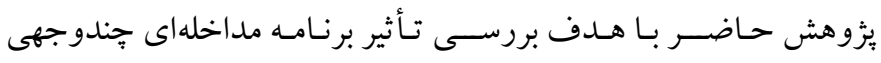

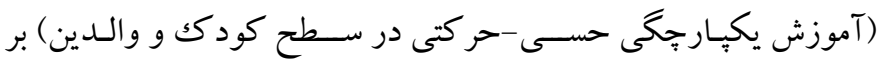


اين موضــوع ييامدهاى روانى - اجتماعى منفى را به دنبال داشــته و بر

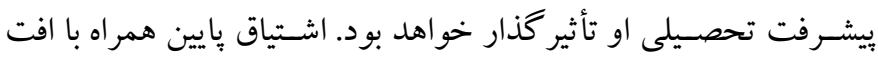

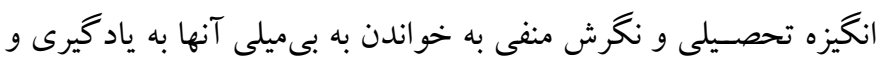

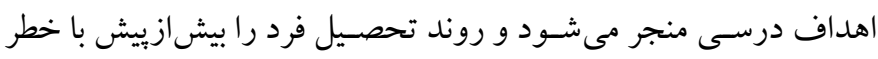
مواجه مى كند.

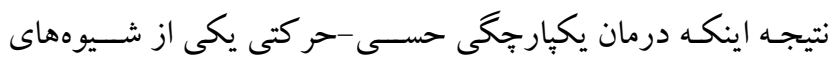

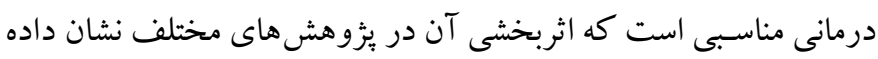

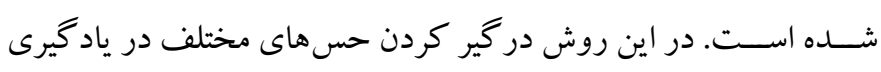
باعث جذاب شـدن تكليف مىشود. علاوه بر اين كود كان علاقه زيادى به دوديه

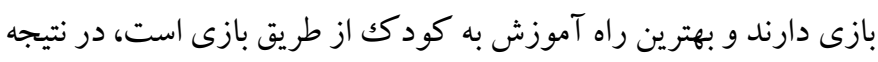

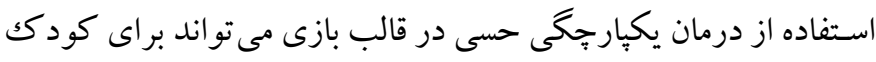

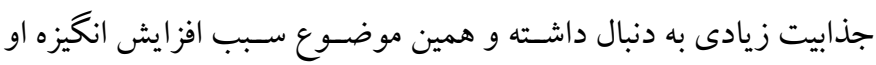

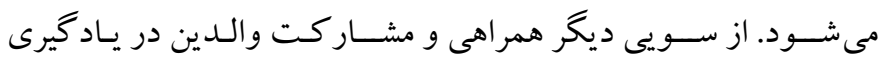

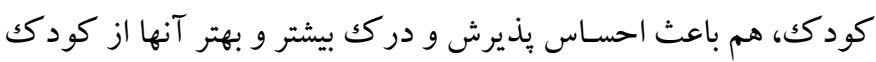

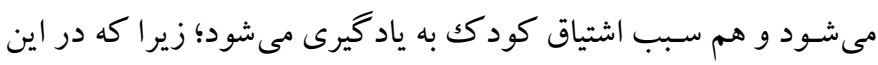

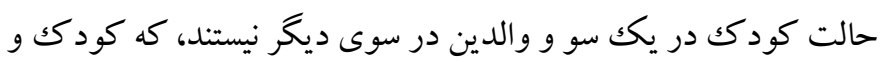
والدين هر دو در يـك جهـت و در يكك زمين بازى قرار دارند و والدين همراه با كود كك در جهت بيشرفت او تلاش مى كنئد.

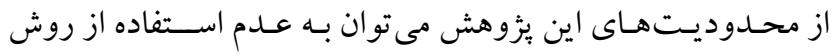

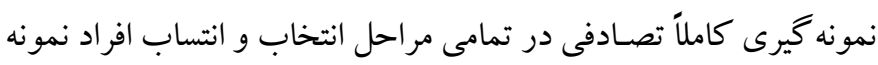

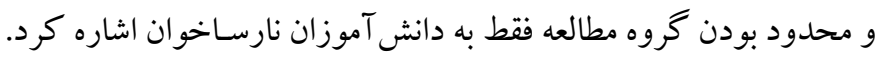

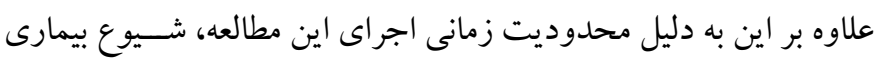

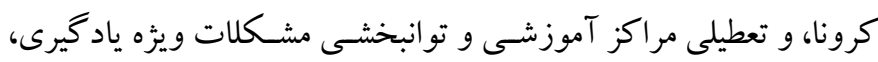

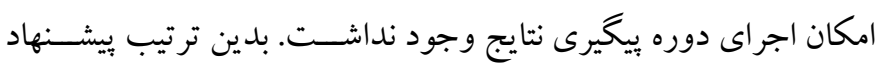

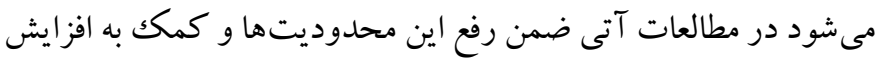

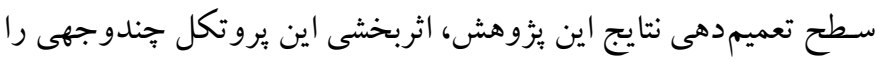

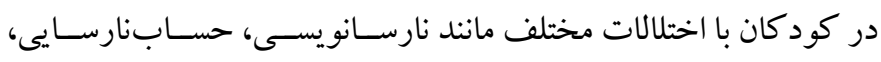

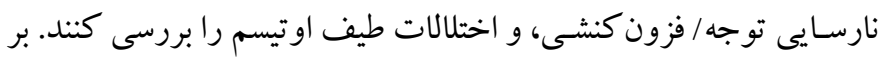
اسـاس نتايج به دسـت آمده در اين مطالعه در سـطح به كار بسـته بيشـنهاد

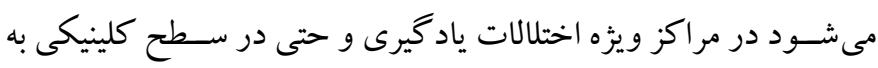
آموزش و درمـان در ســوح مختلف كود كك و والـدين و حتى مربيان، بهور همزمان و هماهنگك تأكيد شود.
كود كـان بـا كم تو انى هاى ياد گيرى مختلف مانند عملكرد خو اندن بهبود

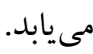

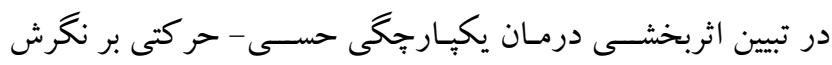

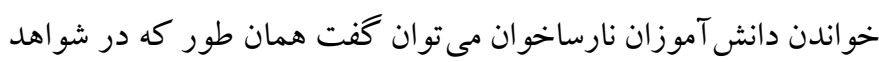

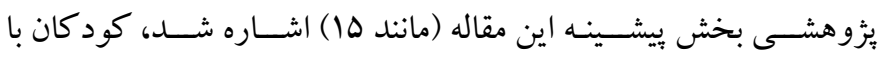

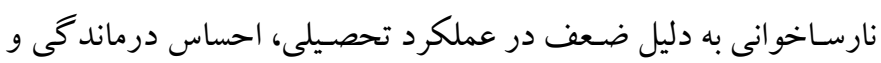

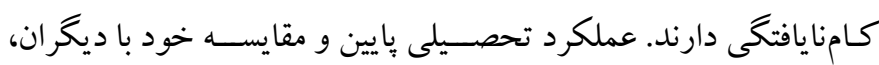

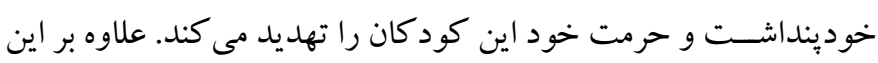
انزوا و طردى كه اين كود كان تجربه مى كنند، ســبب مى شـــود كه آنها بيشازييش احساس كنند كه قادر به بهبود عملكرد تحصيلى خود نيستند

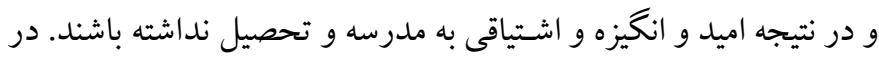

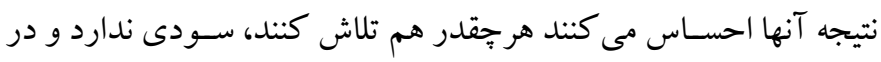

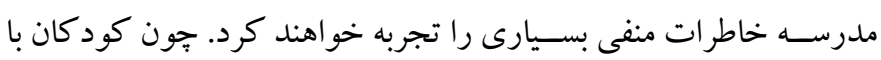

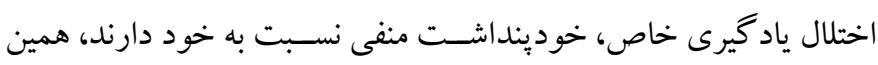

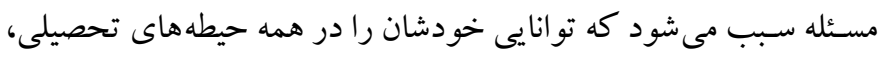

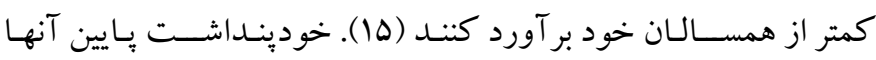

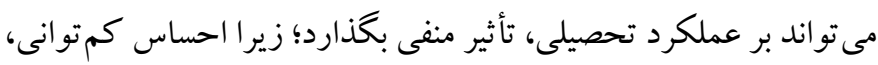

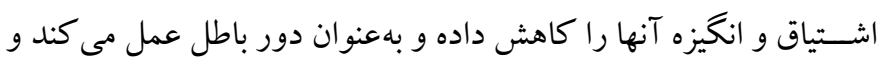
باعث بدتر شدن عملكرد تحصيلى نيز مىشود.

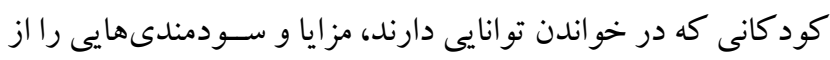

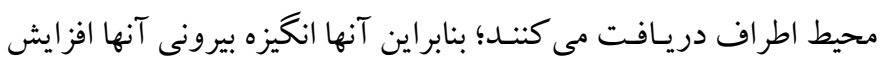

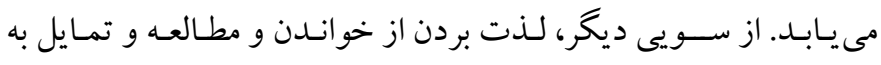

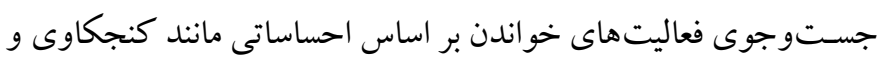

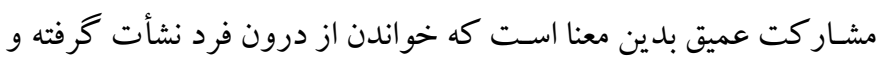

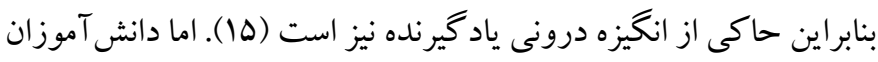

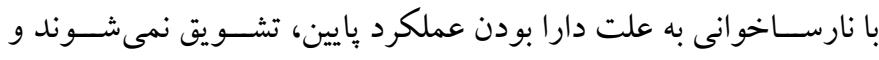

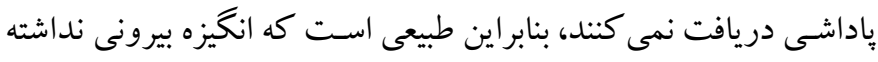

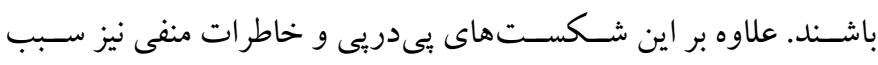

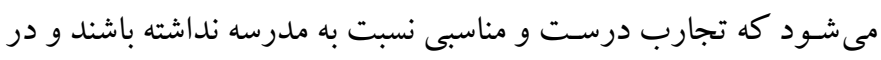

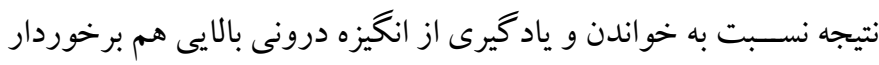

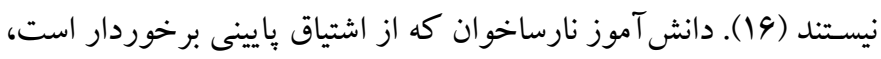

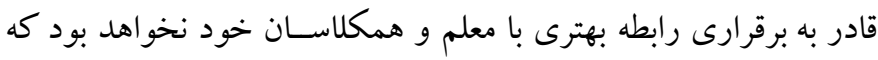


نقش هر يك از نويسـند كان: نويسـنده نخسـت اين مقاله بهعنوان مجرى و طراح

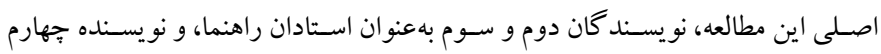
به بهوان استاد مشاور در اين يُووهش نقش داشتهاند.

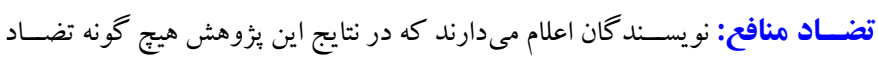

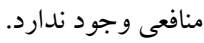
تشكر و قدردانى: بدين وسيله از شر كت كند كان در اين يُروهش شامل دانش آموزان

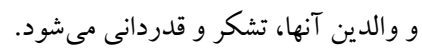

ملاحظات اخلاقى

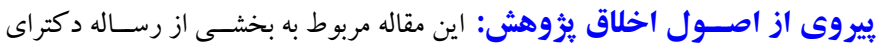

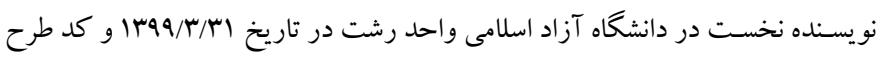

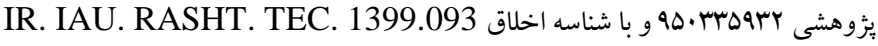

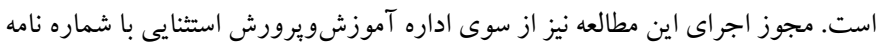
. هل هr/10. ملاحظات اخلاقى مانند رضايت كتبى افراد نمونه بهطور كامل رعايت شده است.

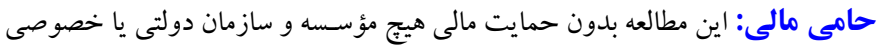

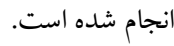




\section{References}

1. National Joint Committee on Learning Disabilities. Learning disabilities: Implications for policy regarding research and practice: A report by the National Joint Committee on Learning Disabilities March 2011. Learning Disability Quarterly; 34(4), 237-241. [Link]

2. Shaywitz SE, Shaywitz BA. Reading disability and the brain. In: Scherer M, editor. On developing readers: Readings from educational leadership (EL essentials). ASCD. 2016, pp: 146-151. [Link]

3. Sainio PJ, Eklund KM, Ahonen TPS, Kiuru NH. The role of learning difficulties in adolescents' academic emotions and academic achievement. J Learn Disabil. 2019; 52(4): 287298. [Link]

4. Tyler EJ, Hughes JC, Beverley M, Hastings RP. Improving early reading skills for beginning readers using an online programme as supplementary instruction. European Journal of Psychology of Education. 2015; 30(3): 281-294. [Link]

5. Roitsch J, Watson S. An overview of dyslexia: definition, characteristics, assessment, identification, and intervention. Science Journal of Education. 2019; 7(4): 81-86. [Link]

6. American Psychiatric Association. Diagnotic and statistical manual of mental disorders (5thed). Arlington، VA: American psychiatric publishing; 2013. [Link]

7. Miller P, Kupfermann A. The role of visual and phonological representations in the processing of Written words by readers with diagnosed dyslexia: Evidence frome a morkings memory task. Dyslexia. 2009; 59(1): 12-33. [Link]

8. Menghini D, Finzi A, Carlesimo G A, Vicari S. Working memory impairment in children with developmental dyslexia: Is it just a phonological deficity. Developmental Neuropsychology. 2011; 36(2): 199-213. [Link]

9. Jeffries S, Everatt J, Working memory: Its role in dyslexia and other specific learning difficulties. Dyslexia. 2004; 10(3): 196-214. [Link]

10. Schuchardt K, Bockmann A، Borneman G، Maehler C. Working memory functioning in children with learning disorders and specific language impairment. Topics in Language Disorders. 2013; 33(4): 298-312. [Link]

11. Alloway $\mathrm{T}$ P. Working memory,but not IQ, predicts subsequent learning in children with learning difficulties. European Journal of Psychological Assessment. 2009; 25(2): 92-98. [Link]

12. Bannach-Brown A. Visual-motor integration in developmental dyslexia. 2014. https: //www. researchgate. net/publication/280045349_Visual-

otor_integration_in_developmental_dyslexia [Link]

13. Crawford SG, Dewey D. Co-occurring disorders: a possible key to visual perceptual deficits in children with developmental coordination disorder? Human Movement Science. 2008; 27(1): 154-69. [Link]

14. Fletcher JM, Lyon GR, Fuchs LS, Barnes MA. Learning disabilities: From identification to intervention. New York: Guilford Press; 2018.[Link]
15. Polychroni F, Koukoura K, Anagnostou I. Academic selfconcept، reading attitudes and approaches to learning of children with dyslexia: do they differ from their peers? European Journal of Special Needs Education. 2006; 21(4): 415-430. [Link].

16. Yahyazadeh A, Karimi R, Hassannia Jorshari M. Motivation. Self -concept and attitudes toward reading in students with dyslexia. J Child Ment Health. 2016; 3 (3): 31-42. [Persian] [Link]

17. Chapman J W, Tunmer W E, Prochnow JE. Early readingrelated skills and performance، reading self-concept، and the development of academic self-concept: A longitudinal study. J Educ Psychol. 2000; 92(4), 703-708. [Link]

18. Wood SE, Wood E G, Boyd D. The world of psychology. social \& applied psychology. Rolling Meadows: IL: Riverside; 2007. [Link]

19. Mihandoost Z, Elias H, Sharifah SH, Mahmud RA. Comparison of the reading motivation and reading attitude of students with dyslexia and students without dyslexia in the elementary schools in Ilam, Iran. International Journal of Psychological Studies. 2011; 3(1): 17-27.[Persian] [Link]

20. Critz C, Blake K, Nogueira E. Sensory processing challenges in children. JNP. 2015; 11(7),710-16. [Link]

21. Humphries T، Wright M، McDougall B، Vertes J. The Efficacy of sensory integration therapy for children with learning disability. Journal Physical \& Occupational Therapy in Pediatrics. 1990; 10,1-17.[Link]

22. Harland A, Swarbrick C, Haines D. The impact of sensory integration groups on the participation of children and young people with learning disabilities: perceptions of therapists and teaching staff. Brighton Journal of Research in Health Sciences. 2017; 3(1): 1-10. [Link]

23. Rajabi Fard F, Esteki M, Poushneh K, Alizadeh M. Effectiveness of sensory learning programs in visual and perceptual skills of children with learning disabilities. International Journal of Psychology and Behavioral Research. 2014; 3،6, 517-525. [Link]

24. Mahvash VA, Parhoon K, Pooshaneh K. The Effectiveness of Sensory-Motor Integration on Balance and Reading Performance in Children with Dyslexia. RBS. 2016; 14 (2): 257-263. [Persian] [Link]

25. Polatajko HJ, Kaplan BJ, Wilson BN. Sensory integration treatment for children with learning disabilities: Its Status 20 Years Later. OTJR. 1992;12(6): 323-341. [Link]

26. Farid F, Kamkary K, Safarinia M, Afroz S. The comparison of diagnostic validity of new version of tehran- stanford binet intelligence scales (TSB-5) and wechsler intelligence scales for children- fourth edition (WISC-4) in children with learning disability. Journal of Learning Disabilities, 2015; 4(2): 70-83. [Persian] [Link]

27. Sadeghi A, Rabiee M, Abedi MR. Validation and reliability of the wechsler intelligence scale for children-IV. Developmental Psychology: Iranian Psychologists. 2011; 7(28): 377-386. [Persian] [Link] 
28. McKenna MC, Kear DJ. Measuring attitude toward reading: A new tool for teachers. Read Teach. 1990; 43(9): 626-639. [Link]

29. Asghari Nekah SM, Saeedi Rezvani M, Azadfar $\mathrm{N}$ ‘, Baghgoli H. Elementary aschool students attitudes towar reading: Differences by gender، classification، economic، social and grade school libraries. School Libraries. 2009:429-444. [Persian] [Link]

30. Ghobari-Bonab B, Afrooz Gh, Hasanzadeh S, ‘ Bakhshi J, Pirzadi H. The impact of teaching active metacognitive thinking-oriented strategies and self monitoring on realing comprehension of students with the reading difficulties. Journal of Learning Disabilities. 2012; 1(2): 77-97. [Persian] [Link]

31. Moradi A, Hosaini M, Kormi Nouri R, Hassani J, Parhoon H. Reliability and validity of reading and dyslexia test (NEMA). Advances in Cognitive Sciences. 2016; 18 (1) :22-34. [Persian] [Link] 